\title{
Salinity and solid fraction of frazil and grease ice
}

\author{
Sönke MAUS, ${ }^{1}$ Sara DE LA ROSA ${ }^{1,2}$ \\ ${ }^{1}$ Geophysical Institute, University of Bergen, Bergen, Norway \\ E-mail: sonke.maus@gfi.uib.no \\ ${ }^{2}$ Nansen Environmental and Remote Sensing Center, Bergen, Norway
}

\begin{abstract}
Under turbulent conditions ice growth in sea water often occurs as tiny suspended frazil ice crystals. When the turbulence is insufficient to keep the crystals in suspension, they may accumulate in a surface grease layer of pure ice and sea water. Here we give an account of this grease of low solid fraction and high salinity prior to its freeze-up into a solid ice cover. We provide equations for determining the bulk salinity, $S_{\mathrm{g}}$, and solid ice volume fraction, $\phi_{\mathrm{s}}$, of the grease layer by indirect and direct methods, review previous observations, and present new data. For the evolution of the solid fraction of accumulating grease ice we find (I) an early mode $0.08<\phi_{\mathrm{s}}<0.12$ and (II) a long-term packing limit of $0.28<\phi_{\mathrm{s}}<0.31$, which for sea water of salinity 34 corresponds to $29.5<S_{\mathrm{g}}<31.5$ and $24<S_{\mathrm{g}}<26$, respectively. We associate (I) with a mechanical limit related to initial random packing of frazil crystals and (II) with a thermodynamic limit, beyond which the grease will freeze-up into a solid ice cover. By comparing the results with a simple model of random close packing of anisotropic particles, we find that the results are consistent with frazil flocs having an aspect ratio of $\sim 10$, much smaller than values assumed in most model applications that include sea-water frazil ice processes.
\end{abstract}

\section{INTRODUCTION}

In his early review of frazil ice, Barnes (1928) says: 'Frazil is a French-Canadian term for fine spicular ice, derived from the French for cinder which this variety of ice most resembles. When formed in saltwater it is known as "lolly ice".' This review was an update of an earlier account of his on ice formation (Barnes, 1906) and demonstrated rapid progress in research on frazil ice formation in rivers. Since then practical problems with river ice have increasingly motivated the study of this topic in northern regions (Altberg, 1936; Devik, 1944). Knowledge of riverine frazil ice has grown significantly (e.g. Michel, 1978; Ashton, 1986; Shen, 1999; Ettema and others, 2009), but many details of the microdynamics and growth of these tiny crystals, from their nucleation to agglomeration and interaction with water currents, are still not fully understood.

Interest in oceanic frazil ice began later than riverine ice research, notably in the 1960s in connection with increasing ocean research activities in Arctic seas (Untersteiner and Sommerfeld, 1964; Coachman, 1966; Lewis and Lake, 1971). Martin (1981) reviewed oceanic settings where frazil ice formation comes into play. The following processes are of note: (1) ice formation and dynamics in turbulent sea water within polynyas and leads (Bauer and Martin, 1983; Pease, 1987; Ushio and Wakatsuchi, 1993); (2) supercooling driven by differential diffusion of heat and salt, when fresh meltwater lies over saline sea water and both are at their respective freezing points (Untersteiner and Sommerfeld, 1964; Martin and Kauffman, 1974; Martin, 1981); (3) upward movement of water that rises from the bottom of icebergs and ice shelves, during which its freezing point increases due to pressure lowering (Jenkins and Bombosch, 1995; Holland and Feltham, 2005); (4) drainage of cold, dense sea-water brine from the bottom of ice sheets (Lake and Lewis, 1970; Martin and others, 1977), which in turn may trigger doublediffusive processes as in (2). In recent years, also (5) the influence of a 'grease ice' cover on the wave field (Martin and Kauffman, 1981; Newyear and Martin, 1997; De Carolis and others, 2005; Wang and Shen, 2010) and (6) sediment suspension dynamics of frazil, including the way in which ice crystals scavenge particles to become 'turbid ice', have become topics of growing interest (Barnes and others, 1982; Kempema and others, 1989; Reimnitz and others, 1993; Ackermann and others, 1994).

Conceptually a 'grease ice' layer forms at the ocean surface when frazil crystals accumulate there. These may be advected horizontally, or rise to the surface when turbulence due to waves and currents disrupts the frazil ice suspension. Processes (1), (5) and (6) not only depend strongly on oceanic turbulence, but also on the interaction of frazil crystals with each other, the way in which they cluster and grow, their distribution in the water column, and their rise to the surface and compaction into a grease ice cover of a certain thickness. On the one hand, surface turbulence due to waves and current shear is an ongoing open research field. On the other hand, sampling of frazil and grease ice is difficult under harsh climatic conditions. The interaction of these processes is thus still insufficiently observed and modelled. Even our present knowledge of the solid ice volume fraction and salinity of grease ice, which may be sampled from the ocean surface, is limited to a few field and laboratory studies that have employed different observational techniques (Cherepanov and Kozlovskii, 1973; Martin and Kauffman, 1981; Reimnitz and others, 1993; Gradinger and Ikävalko, 1998; Wadhams and Wilkinson, 1999; Doble and others, 2003; Smedsrud and Skogseth, 2006). Besides the thickness of a grease ice layer, it is its solid volume fraction that determines its dynamic and thermodynamic behaviour. The solid ice volume fraction affects the viscosity of the grease layer (Newyear and Martin, 1997) and is therefore fundamental in describing ocean surface dynamics under the presence of frazil ice formation. As a higher solid fraction implies a lower bulk grease salinity, a consistent description of surface grease thermodynamics and conservation of mass and salt is also important when salt fluxes into the ocean are considered (e.g. Martin and Kauffman, 1981; Ushio and Wakatsuchi, 1993). 
The present paper revises methods of estimating the solid volume fraction of grease ice, i.e. its volumetric fraction occupied by ice crystals, by observation. After formulating the mathematical background, we review previous investigations and their uncertainties. We then present possible explanations for the observed differences, and a detailed analysis of observations from a recent experimental laboratory study (Wang and Shen, 2010; De la Rosa and Maus, 2011; De la Rosa and others, 2011). In the results section, we discuss the temporal and vertical evolution of the grease ice solid fraction that was obtained from the reviewed studies. We then present possible explanations of the observed differences by an analysis and discussion of the compaction of grease in terms of simple models of accumulation and packing.

\section{EQUATIONS FOR THE SOLID FRACTION OF GREASE ICE}

We begin with the basic equations that may be used to determine the salinity and solid fraction of grease ice, directly and indirectly from observations. In the following analysis it is first assumed that grease ice is a two-phase mixture of ice (solid) and sea water or brine (liquid), and free of air (gas). Corrections for air inclusions are later introduced. The grease ice may have accumulated at the surface, or may be actively forming in the water column; in each case we are considering a sample volume $V_{\mathrm{g}}$. Denoting the mass, $M$, volume, $V$, and density, $\rho$, of grease, solid ice and brine with subscripts ' $\mathrm{g}$ ', ' $\mathrm{i}$ ' and ' $\mathrm{b}$ ', respectively, volume $V_{\mathrm{g}}$ is the sum of pure ice and brine

$$
V_{\mathrm{g}}=V_{\mathrm{i}}+V_{\mathrm{b}}
$$

while mass conservation reads

$$
M_{\mathrm{g}}=M_{\mathrm{i}}+M_{\mathrm{b}}
$$

or, with $M=\rho V$, takes the form

$$
\rho_{\mathrm{g}} V_{\mathrm{g}}=\rho_{\mathrm{i}} V_{\mathrm{i}}+\rho_{\mathrm{b}} V_{\mathrm{b}}
$$

We define the liquid volume fraction of grease ice as $\phi_{\mathrm{b}}=$ $V_{\mathrm{b}} / V_{\mathrm{g}}$ and the solid fraction as $\phi_{\mathrm{s}}=V_{\mathrm{i}} / V_{\mathrm{g}}$. In the absence of gas, one has $\phi_{\mathrm{s}}+\phi_{\mathrm{b}}=1$ and thus

$$
\phi_{\mathrm{s}}=1-\phi_{\mathrm{b}}=\frac{V_{\mathrm{i}}}{V_{\mathrm{g}}}=\frac{V_{\mathrm{i}}}{V_{\mathrm{i}}+V_{\mathrm{b}}} .
$$

The salinity is defined as a mass ratio, i.e. as the weight of salt per weight of brine, $S_{\mathrm{b}}$, ice, $S_{\mathrm{i}}$, or their respective grease (ice and brine) mixture, $S_{\mathrm{g}}$. The salt conservation for grease,

$$
S_{\mathrm{g}} \rho_{\mathrm{g}} V_{\mathrm{g}}=S_{\mathrm{i}} \rho_{\mathrm{i}} V_{\mathrm{i}}+S_{\mathrm{b}} \rho_{\mathrm{b}} V_{\mathrm{b}}
$$

may be written in the form

$$
S_{\mathrm{g}} \rho_{\mathrm{g}} V_{\mathrm{g}}=S_{\mathrm{b}} \rho_{\mathrm{b}} V_{\mathrm{b}}\left(1+k_{\mathrm{e}} \frac{\rho_{\mathrm{i}}}{\rho_{\mathrm{b}}} \frac{V_{\mathrm{i}}}{V_{\mathrm{b}}}\right),
$$

with $k_{\mathrm{e}}=S_{\mathrm{i}} / S_{\mathrm{b}}$. The ratio, $k_{\mathrm{e}}$, of the salinity of ice crystals to that of the solution from which they grow is often termed the effective solute distribution coefficient (Weeks and Lofgren, 1967; Tiller, 1991) and, for dilute saline solutions, is $<10^{-3}$ (Gross and others, 1977; Thibert and Domine, 1997). However, for freezing of more concentrated sea water, the low solubility of chlorine in ice (e.g. Thibert and Domine, 1997) limits $S_{\mathrm{i}} / S_{\mathrm{b}}$ to values less than $10^{-4}$.
As both $\rho_{\mathrm{i}} / \rho_{\mathrm{b}}$ and $V_{\mathrm{i}} / V_{\mathrm{b}}$ are $\sim 1$, for natural grease ice considered here, we neglect the $k_{\mathrm{e}}$ term and write Eqn (6) as

$$
S_{\mathrm{g}} \rho_{\mathrm{g}} V_{\mathrm{g}} \approx S_{\mathrm{b}} \rho_{\mathrm{b}} V_{\mathrm{b}}
$$

The salinity, $S_{g}$, of grease ice may be determined in a relatively simple manner, by melting a grease ice sample and measuring its electrolytic conductivity and temperature. Determination of the solid fraction, $\phi_{s}$, by observation is less straightforward since it requires knowledge of the relative volumes of ice and brine. We now consider four approaches to obtain the solid fraction and/or salinity of grease ice from observations.

\section{Methods}

\section{(1) $\phi_{\mathrm{s}}$ from grease ice bulk salinity}

If the very small salt content of ice crystals is neglected $\left(k_{\mathrm{e}} \ll 1\right)$, the solid fraction may be obtained from measurements of grease bulk salinity, $S_{\mathrm{g}}$, and the salinity, $S_{\mathrm{b}}$, of its brine. $S_{\mathrm{g}}$ is normally obtained from a sample melted in a closed container. Another simple method to obtain $S_{\mathrm{b}}$ is to first separate brine from the sample by draining it, measure the brine salinity and finally merge the brine sample again with the melted ice sample to measure $S_{\mathrm{g}}$. Combining Eqns (7) and (4) one may first write

$$
\phi_{\mathrm{s}}=1-\frac{S_{\mathrm{g}} \rho_{\mathrm{g}}}{S_{\mathrm{b}} \rho_{\mathrm{b}}} .
$$

Here $\rho_{\mathrm{g}}$ on the right-hand side still depends on $\phi_{\mathrm{s}}$. However, neglecting the density difference between grease ice and brine, one may approximate $\phi_{\mathrm{s}} \approx\left(1-S_{\mathrm{g}} / S_{\mathrm{b}}\right)$, a well-known rule of thumb. Nevertheless, for low solid fractions, when $\rho_{\mathrm{g}} / \rho_{\mathrm{b}}$ becomes comparable with $S_{\mathrm{g}} / S_{\mathrm{b}}$, this approximation implies large errors. To obtain the correct $\phi_{\mathrm{s}}$ we substitute $\rho_{\mathrm{g}}$ from Eqn (3) in Eqn (8), giving

$$
\phi_{\mathrm{s}}=1-\left[1+\left(\frac{S_{\mathrm{b}}}{S_{\mathrm{g}}}-1\right) \frac{\rho_{\mathrm{b}}}{\rho_{\mathrm{i}}}\right]^{-1} .
$$

At typical sea-water freezing temperatures the density, $\rho_{\mathrm{b}}$, is only a weak function of temperature. For our purposes it suffices to approximate it as

$$
\rho_{\mathrm{b}}=\rho_{0}+\beta S_{\mathrm{b}}
$$

where $\rho_{0}$ is a reference density of fresh water and $\beta$ a haline contraction coefficient (e.g. Ono, 1967; Pounder, 1965; Doronin and Kheisin, 1977). For the small temperature ranges considered, $\beta$ and also the pure ice density, $\rho_{\mathrm{i}}$, can be assumed constant. Hence, Eqn (9) can be used to obtain the solid ice fraction, $\phi_{\mathrm{s}}$, of grease on the basis of observations of its bulk salinity, $S_{\mathrm{g}}$, and its brine salinity, $S_{\mathrm{b}}$, alone. Thereby the liquid fraction, or brine porosity, is given as $\phi_{\mathrm{b}}=\left(1-\phi_{\mathrm{s}}\right)$.

We now consider grease ice that contains air (or gas). This may either be the case due to natural gas entrapment processes, due to some brine loss during sampling, or because a sample has been drained. Instead of Eqn (4), now $\phi_{\mathrm{s}}$ is given by

$$
\phi_{\mathrm{s}}=1-\phi_{\mathrm{b}}-\phi_{\mathrm{a}}
$$

which includes $\phi_{\mathrm{a}}=V_{\mathrm{a}} / V_{\mathrm{g}}$, the fractional air volume. Assuming that gas contains no salt, Eqn (7) remains the same, and Eqn (8) becomes

$$
\phi_{s}=1-\frac{S_{\mathrm{g}} \rho_{\mathrm{g}}}{S_{\mathrm{b}} \rho_{\mathrm{b}}}-\phi_{\mathrm{a}}
$$


Comparing Eqn (12) with Eqn (8) shows that in this approach based on bulk grease salinity the solid fraction, $\phi_{\mathrm{s}}$, is overestimated by the fractional air volume, $\phi_{\mathrm{a}}$.

\section{(2) $\phi_{\mathrm{s}}$ from densities or mass and volume}

A second approach makes use of the different densities of water and ice. Writing Eqn (4) in the form

$$
\phi_{\mathrm{s}}=\frac{V_{\mathrm{i}}}{V_{\mathrm{g}}}=\frac{M_{\mathrm{i}}}{V_{\mathrm{g}} \rho_{\mathrm{i}}}
$$

shows that $\phi_{\mathrm{S}}$ could be obtained by measuring the total volume, $V_{\mathrm{g}}$, of a grease sample and the volume, $V_{\mathrm{i}}$, of solid ice crystals. While, due to the different shapes of crystals, it is difficult to determine $V_{\mathrm{i}}$ by standard methods, it is more natural to determine the solid ice mass, $M_{\mathrm{i}}=V_{\mathrm{i}} \rho_{\mathrm{i}}$. A practical approach is to sieve or filter a known grease ice volume, and measure the mass of the sieved sample. However, this is limited by the fact that liquid adheres to crystals. Actually, one would not measure $M_{i}$, the mass of solid ice, but $M_{\mathrm{g}}^{\prime}$, the grease ice mass after sieving off some, but not all, of the liquid. Also the density in Eqn (13) is not $\rho_{\mathrm{i}}$, but the corresponding density, $\rho_{\mathrm{g}}^{\prime}$, which is unknown. The use of Eqn (13) with the drained ice mass, $M_{\mathrm{g}}^{\prime}$, inserted for $M_{\mathrm{i}}$ will thus overestimate $\phi_{\mathrm{s}}$, mostly because $M_{\mathrm{g}}^{\prime}>M_{\mathrm{i}}$. However, the contribution of the adhering brine fraction can be computed from the salt budget, if in addition the salinity, $S_{g}^{\prime}$, of the (not pure) ice of mass $M_{\mathrm{g}}^{\prime}$ is measured. This is shown below and leads to Eqn (24).

Alternatively, Eqn (3) may be combined with Eqn (4) to obtain

$$
\phi_{\mathrm{s}}=\frac{\rho_{\mathrm{b}}-\rho_{\mathrm{g}}}{\rho_{\mathrm{b}}-\rho_{\mathrm{i}}} .
$$

This equation yields the solid fraction on the basis of density measurements of bulk grease, $\rho_{\mathrm{g}}$, and brine, $\rho_{\mathrm{b}}$, again with the solid ice density, $\rho_{\mathrm{i}}$, assumed constant. It is possible to measure $\rho_{\mathrm{g}}$ by filling a container or flask of known volume with grease ice and measuring its weight. As $\rho_{\mathrm{b}}$ depends on brine salinity, $S_{\mathrm{b}}$, through Eqn (10), one again needs to measure the brine salinity to calculate it. From the density approximation for sea water it can be seen that the relative variability of $\rho_{\mathrm{b}}$ due to expected variations in $S_{\mathrm{b}}$ is weak. One may thus obtain $\phi_{\mathrm{s}}$ from $\rho_{\mathrm{g}}$ by using the sea-water salinity as an approximate estimate for $S_{\mathrm{b}}$.

The main limitation of Eqn (14) is that it is based on the relatively small density difference of brine and grease ice. If $\rho_{\mathrm{g}}$ is close to $\rho_{\mathrm{b}}$, as in the case of low solid fractions, then only a small amount of air may have a strong impact on the results. To evaluate this impact, one combines Eqn (11), which includes air as a volume fraction, with Eqn (3), thereby neglecting the small mass of air. This gives

$$
\phi_{\mathrm{s}}=\frac{\rho_{\mathrm{b}}-\rho_{\mathrm{g}}-\rho_{\mathrm{b}} \phi_{\mathrm{a}}}{\rho_{\mathrm{b}}-\rho_{\mathrm{i}}} .
$$

Comparing this result with Eqn (14), it gives the corrected solid fraction of gas-containing grease ice, based on measured grease density, $\rho_{\mathrm{g}}$, and measured (or estimated) brine density, $\rho_{\mathrm{b}}$, provided that the air volume fraction, $\phi_{\mathrm{a}}$, is known. Normally, as the latter is more difficult to measure, the equation will give the sensitivity of calculations of $\phi_{\mathrm{s}}$ to the unknown air volume.

\section{(3) $\phi_{\mathrm{s}}$ from grease ice density and salinity}

Both methods introduced so far require observations of some brine properties. Sampling of brine may be difficult in practice, and also implies separation of a bulk sample. It is thus useful to eliminate all brine properties to obtain a method based on grease bulk properties alone. Combining Eqns (8) and (14) one obtains

$$
\frac{S_{\mathrm{g}} \rho_{\mathrm{g}}}{S_{\mathrm{b}} \rho_{\mathrm{b}}}=\frac{\rho_{\mathrm{g}}-\rho_{\mathrm{i}}}{\rho_{\mathrm{b}}-\rho_{\mathrm{i}}} .
$$

Replacing $\rho_{\mathrm{b}}$ using Eqn (10) yields

$$
a S_{\mathrm{b}}^{2}+b S_{\mathrm{b}}+c=0,
$$

wherein $\mathrm{a}=\beta\left(\rho_{\mathrm{g}}-\rho_{\mathrm{i}}\right), \quad b=\left[\rho_{0}\left(\rho_{\mathrm{g}}-\rho_{\mathrm{i}}\right)-S_{\mathrm{g}} \beta \rho_{\mathrm{g}}\right]$ and $c=S_{\mathrm{g}} \rho_{\mathrm{g}}\left(\rho_{\mathrm{i}}-\rho_{0}\right)$, giving the solution

$$
S_{\mathrm{b}}=\frac{\left(b^{2}-4 a c\right)^{1 / 2}-b}{2 a}
$$

for the brine salinity. The solid fraction is then obtained, by inserting $S_{\mathrm{b}}$ in Eqn (10) for $\rho_{\mathrm{b}}$, and combining with Eqn (8) as

$$
\phi_{\mathrm{s}}=1-\frac{S_{\mathrm{g}} \rho_{\mathrm{g}}}{S_{\mathrm{b}}\left(\rho_{0}+\beta S_{\mathrm{b}}\right)} .
$$

As $\beta, \rho_{\mathrm{i}}$ and $\rho_{0}$ are constants, this approach gives the brine salinity on the basis of the bulk grease ice variables alone: grease salinity, $S_{g}$, and density, $\rho_{\mathrm{g}}$. In practice, these properties may be measured by sampling grease ice into a container of known volume, melting the sample, then measuring its mass and salinity. Then, from the measured $S_{\mathrm{g}}$ and $\rho_{\mathrm{g}}$ the brine salinity, $S_{\mathrm{b}}$, is obtained via Eqn (18), and inserted into Eqn (19) to obtain the solid fraction.

However, also in this approach the brine salinity depends, via $a$ and $b$ in Eqn (18), on density differences, and may be strongly affected by the presence of small amounts of air. An air correction to method 3, based on grease ice salinity and density, may now be obtained by combining Eqn (12) with Eqn (15). This gives

$$
\frac{S_{\mathrm{g}} \rho_{\mathrm{g}}}{S_{\mathrm{b}} \rho_{\mathrm{b}}}=\frac{\rho_{\mathrm{g}}-\rho_{\mathrm{i}}\left(1-\phi_{\mathrm{a}}\right)}{\rho_{\mathrm{b}}-\rho_{\mathrm{i}}} .
$$

From here one may proceed in the same manner to obtain $S_{\mathrm{b}}$ and $\phi_{\mathrm{s}}$, with the only difference that now $\left[\rho_{\mathrm{g}}-\rho_{\mathrm{i}}\left(1-\phi_{\mathrm{a}}\right)\right]$ replaces $\left(\rho_{\mathrm{g}}-\rho_{\mathrm{i}}\right)$ in Eqn (17). This procedure allows for an evaluation of the influence of the air volume on the calculated brine salinity and solid fraction of grease, when only grease ice salinity and density are measured. However, an interesting aspect arises from this discussion: if in addition $S_{\mathrm{b}}$ is measured, the calculations can be easily inverted to estimate the air fraction, $\phi_{\mathrm{a}}$.

\section{(4) $\phi_{\mathrm{s}}$ from drained grease samples}

The potential, in method 3, to use additional measurements of $S_{\mathrm{b}}$ to estimate the air volume fraction, $\phi_{\mathrm{a}}$, has another application. When brine is lost during sampling, or when it is sieved from the grease ice for further analysis, an artificial $\phi_{\mathrm{a}}$ is generated. Neglecting the (presumably smaller) air content before drainage, this fraction corresponds to drained brine and needs to be known to calculate the in situ grease salinity. In terms of measurable properties, a typical situation in practice is the following: during standard sampling one may observe $V_{\mathrm{g}}$, the volume of the grease sample before drainage, its mass, $M_{g}^{\prime}$, and salinity, $S_{g}^{\prime}$, after drainage, and eventually the salinity, $S_{\mathrm{b}}$, of the drained brine. From these 
observations one wants to obtain the solid fraction, $\phi_{\mathrm{S}}$, and salinity, $S_{g}$, of the grease before drainage. In this situation we consider that the brine volume, $V_{d}$, is lost from a grease ice sample of volume $V_{\mathrm{g}}$, initial brine volume $V_{\mathrm{b}}$ and density $\rho_{\mathrm{b}}$. After drainage it is replaced by air of density $\rho_{\mathrm{a}}$. In the following, all frazil properties after drainage are denoted as $V_{\mathrm{g}}^{\prime}, \rho_{\mathrm{g}}^{\prime}$ and $S_{\mathrm{g}}^{\prime}$. The grease ice mass, $M_{\mathrm{g}}^{\prime}$, after this drainage loss becomes

$$
M_{\mathrm{g}}^{\prime}=\rho_{\mathrm{i}} V_{\mathrm{i}}+\rho_{\mathrm{b}}\left(V_{\mathrm{b}}-V_{\mathrm{d}}\right)+\rho_{\mathrm{a}} V_{\mathrm{d}}
$$

As $\rho_{\mathrm{a}} / \rho_{\mathrm{i}} \approx 10^{-3}$ we again neglect the term $\rho_{\mathrm{a}} V_{\mathrm{d}}$ on the righthand side. As long as $V_{\mathrm{d}}$ is not much larger than $V_{\mathrm{b}}$ and $V_{\mathrm{i}}$, this has a very small $\left(\sim 10^{-3}\right)$ impact on the following results. To obtain a solution in terms of measurable properties, one divides Eqn (21) by the grease volume, $V_{\mathrm{g}}$, before drainage, giving

$$
\frac{M_{\mathrm{g}}^{\prime}}{V_{\mathrm{g}}}=\rho_{\mathrm{i}} \phi_{\mathrm{s}}+\rho_{\mathrm{b}} \phi_{\mathrm{r}},
$$

where a reduced or residual brine volume fraction, $\phi_{\mathrm{r}}=$ $\phi_{\mathrm{b}}-\phi_{\mathrm{d}}=\left(V_{\mathrm{b}}-V_{\mathrm{d}}\right) / V_{\mathrm{g}}$, is defined and $\phi_{\mathrm{d}}=V_{\mathrm{d}} / V_{\mathrm{g}}$ is the drained volume fraction. Note that $\phi_{\mathrm{r}}$ and $\phi_{\mathrm{d}}$ relate, like $\phi_{\mathrm{b}}$ and $\phi_{\mathrm{s}}$, to the undrained grease volume, $V_{\mathrm{g}}$. In accord with Eqn (7), the salinity $S_{\mathrm{g}}^{\prime}$, of the drained grease obeys $S_{\mathrm{g}}^{\prime} M_{\mathrm{g}}^{\prime}=S_{\mathrm{b}} \rho_{\mathrm{b}}\left(V_{\mathrm{b}}-V_{\mathrm{d}}\right)$ and thus

$$
\frac{S_{\mathrm{g}}^{\prime} M_{\mathrm{g}}^{\prime}}{V_{\mathrm{g}}}=S_{\mathrm{b}} \rho_{\mathrm{b}} \phi_{\mathrm{r}}
$$

Combining Eqns (22) and (23) to eliminate $\phi_{\mathrm{r}}$ then yields

$$
\phi_{\mathrm{s}}=\frac{M_{\mathrm{g}}^{\prime}}{V_{\mathrm{g}} \rho_{\mathrm{i}}}\left(1-\frac{S_{\mathrm{g}}^{\prime}}{S_{\mathrm{b}}}\right),
$$

the in situ solid fraction, before drainage. From the latter we now obtain the in situ grease ice salinity by inverting Eqn (9) as

$$
S_{\mathrm{g}}=S_{\mathrm{b}}\left[1+\frac{\rho_{\mathrm{i}}}{\rho_{\mathrm{b}}}\left(\frac{\phi_{\mathrm{s}}}{1-\phi_{\mathrm{s}}}\right)\right]^{-1} .
$$

Hence, the solid volume fraction and salinity of grease ice before drainage, $S_{\mathrm{g}}$ and $\phi_{\mathrm{s}}$, can be obtained from observations of the salinity and mass of grease ice after drainage, $S_{\mathrm{g}}^{\prime}$ and $M_{\mathrm{g}}^{\prime}$, and the volume, $V_{\mathrm{g}}$, of the grease sample before drainage, provided that the brine salinity, $S_{\mathrm{b}}$, is known. Note that Eqn (24) is the appropriate extension of Eqn (13), because for most practical situations complete drainage of brine, on which the latter is based, cannot be attained.

Combining Eqns (23) and (24) one can compute

$$
\phi_{\mathrm{r}}=\phi_{\mathrm{s}} \frac{S_{\mathrm{g}}^{\prime} \rho_{\mathrm{i}}}{S_{\mathrm{b}} \rho_{\mathrm{b}}}\left(1-\frac{S_{\mathrm{g}}^{\prime}}{S_{\mathrm{b}}}\right)^{-1},
$$

which is the liquid volume fraction of the grease after drainage, with respect to its volume, $V_{g}$, before drainage. This liquid, adhering to the crystals or being entrapped between them, in turn gives the brine volume fraction, $\phi_{\mathrm{d}}=\phi_{\mathrm{b}}-\phi_{\mathrm{r}}$, that has been drained.

We note that the above formulation assumes that the volume of a sample is not changed while the drained brine is replaced by air. Following this definition, $\phi_{\mathrm{S}}$ is unchanged during drainage. Also $\phi_{\mathrm{b}}$ does not change and is rather split into a drained $\left(\phi_{\mathrm{d}}\right)$ and residual $\left(\phi_{\mathrm{r}}\right)$ component. However, as discussed later, one may be interested in the solid volume fraction, $\phi_{s}^{\prime}$, of the drained frazil crystals without considering the air (drained brine). This $\phi_{\mathrm{s}}^{\prime}$ is defined as a fraction of the reduced sample volume, $V_{\mathrm{g}}^{\prime}=V_{\mathrm{g}}-V_{\mathrm{d}}$. To avoid confusion, recall that $\phi_{\mathrm{s}}$ and $\phi_{\mathrm{b}}$ always relate to 'undrained grease ice', while $\phi_{\mathrm{s}}^{\prime}$ and $\phi_{\mathrm{b}}^{\prime}=1-\phi_{\mathrm{s}}^{\prime}$ are volume fractions that refer to 'drained grease' or 'frazil crystals'. The latter can be computed from Eqn (8) using the salinity, $S_{g}^{\prime}$, of drained ice, if $S_{\mathrm{b}}$ is known. In our framework it is related to the derived properties for the undrained grease via $\phi_{\mathrm{s}}^{\prime}=\phi_{\mathrm{s}} /\left(1-\phi_{\mathrm{d}}\right)=$ $\phi_{\mathrm{s}} /\left(\phi_{\mathrm{s}}+\phi_{\mathrm{r}}\right)$. Finally, note that $\phi_{\mathrm{b}}^{\prime} V_{\mathrm{g}}^{\prime}$, the dimensional liquid volume of the frazil crystals, numerically equals $\phi_{\mathrm{r}} V_{\mathrm{g}}$, the residual liquid volume of grease ice after drainage.

\section{Practical limitations, uncertainty and sensitivity}

We have discussed four approaches from which the solid fraction of grease ice may be derived. Before we compare them with observations, we discuss their practical applicability and uncertainties. The following calculations are based on freezing-point and density/salinity relationships (neglecting the weak temperature dependence) for sea water and $\mathrm{NaCl}$ model solutions, summarized by Maus (2007) (see also Kaufmann, 1960; Fofonoff and Millard, 1983; Zaytsev and Aseyev, 1992). In accordance with the practical salinity definition for sea water, the salinity is henceforth given dimensionless (e.g. Millero and others, 2008) and one unit refers to a $1.005 \mathrm{~g} \mathrm{~kg}^{-1}$ salt solution for sea water. We also use this definition in reference to $1 \mathrm{~g} \mathrm{~kg}^{-1}$ for the $\mathrm{NaCl}$ based studies mentioned herein. The density approximation for sea water is $\rho_{\mathrm{b}}=\rho_{0}+\beta S_{\mathrm{b}}$, with $\rho_{0}=1000 \mathrm{~kg} \mathrm{~m}^{-3}$ and $\beta=0.81 \mathrm{~g} \mathrm{~m}^{-3}$, while for $\mathrm{NaCl}$ solutions a slightly smaller $\beta=0.77 \mathrm{~g} \mathrm{~m}^{-3}$ applies. A constant pure ice density, $\rho_{\mathrm{i}}=$ $917.0 \mathrm{~kg} \mathrm{~m}^{-3}$, is used.

From the derivations so far it is clear that uncertainties in the calculated solid fraction are expected due to two factors, first the unknown brine salinity, $S_{\mathrm{b}}$, or the assumption that it corresponds to the salinity of sea water and, second, the unknown air content, $\phi_{\mathrm{a}}$. The brine salinity, $S_{\mathrm{b}}$, is a common term in all equations. Its deviation from the often known seawater salinity is thus important to evaluate their uncertainty. Also, under freezing conditions it may be more practical to determine $S_{\mathrm{b}}$ directly from temperature measurements, sticking a probe into the grease ice layer. Near the salinity of standard sea water, $S_{\mathrm{w}}=35$, the freezing point, $T_{\mathrm{f}}$, varies with salinity by $\mathrm{d} T_{\mathrm{f}} / \mathrm{d} S \approx-0.057^{\circ} \mathrm{Cpsu}^{-1}$ for sea water and by $-0.062^{\circ} \mathrm{Cg}^{-1} \mathrm{~kg}^{-2}$ for $\mathrm{NaCl}$ solutions. (Note psu indicates 'practical salinity units'. For oceanic sea water this is very close to $1 \mathrm{ppt}$ ) Since grease ice temperatures $>0.1 \mathrm{~K}$ below the freezing point of the underlying sea water have, except for the thin surface film, not yet been reported (Martin and others, 1977; Martin and Kauffman, 1981; Ushio and Wakatsuchi, 1993), one may assume a $0.1 \mathrm{~K}$ lower grease ice temperature for the investigated grease layer to estimate an upper bound of 1.7 (1.6) higher salinity than sea water ( $\mathrm{NaCl}$ solution). Ushio and Wakatsuchi (1993) reported brine salinities within laboratory-grown grease ice that were 0.5-1 above the water salinities, while Reimnitz and others (1993) found $0.4-1.9$ higher brine salinities. Hence, $1 \mathrm{~g} \mathrm{~kg}^{-1}$, or simply a dimensionless salinity of 1 , as used here, appears to be a reasonable estimate for the brine salinity excess and is assumed in the following. With regard to the air porosity for grease ice, we are not aware of any observations. However, for young laboratory and field samples of solid ice, Nakawo (1983) reported values mostly in the range $0.005<\phi_{\mathrm{a}}<0.015$. Only at the surface and near the bottom were values as high as 0.03-0.05 observed, probably 
due to brine drainage from the freeboard, and loss from the bottom during sampling. Similar gas content measurements of laboratory-grown sea ice were presented by Tison and others (2002). Hence, we may consider $\phi_{\mathrm{a}}=0.01$ as a typical air porosity that will affect the four observational methods as follows.

\section{(1) $\phi_{\mathrm{s}}$ based on grease bulk salinity}

Equation (9) additionally requires measurements of brine salinity $S_{\mathrm{b}}$, yet if the salinity of sea water is used as an approximation for $S_{\mathrm{b}}$, the method is much simpler. We can, neglecting density differences in Eqn (7), estimate the sensitivity to a deviation of $S_{\mathrm{b}}$ from the sea-water value as $\mathrm{d} \phi_{\mathrm{b}} / \mathrm{d} S_{\mathrm{b}}=-\mathrm{d} \phi_{\mathrm{s}} / \mathrm{d} S_{\mathrm{b}} \approx-S_{\mathrm{g}} / S_{\mathrm{b}}^{2}$. For standard sea water with $S_{\mathrm{b}} \approx 35$ and typical grease ice salinities $\left(25<S_{\mathrm{g}}<\right.$ 31 in the present study; see below) this corresponds to a solid fraction increase of $0.020-0.025$ per unit brine salinity increase. The grease of highest salinity has low solid fraction $\left(\phi_{\mathrm{s}} \approx 0.05-0.10\right.$, discussed later); the relative underestimate of $\phi_{\mathrm{s}}$ due to the sea-water approximation can be up to $50 \%$. As seen from Eqn (12), the effect of air porosity is simply additive, and neglecting it will overestimate the solid fraction by $\phi_{\mathrm{a}}$ (typically 0.01 ). Note that the grease ice salinity also enters into Eqn (12), but as it can be measured by standard methods (electrolytic conductivity) with $0.5 \%$ relative accuracy, its effect on the uncertainty of $\phi_{\mathrm{s}}$ is much smaller than that of $S_{\mathrm{b}}$ and $\phi_{\mathrm{a}}$.

\section{(2) $\phi_{s}$ based on grease and brine densities}

In Eqn (13) the solid fraction relates to grease volume, $V_{g}$, and (pure) ice mass, $M_{\mathrm{i}}$, and its accuracy is determined by the accuracy to which these two properties can be measured. More importantly, its applicability is limited by the fact that it does not account for liquid brine adhering to frazil crystals (e.g. after these have been sieved to remove the brine). High uncertainty is implied, as the liquid fraction may be 30$70 \%$, depending on experimental conditions and drainage protocol.

Furthermore, Eqn (14) is based on measurements of the grease ice density. Also here observations of the brine density are required or, alternatively, one needs to use the sea-water approximation for the brine. From Eqns (14) and (4) we obtain $\mathrm{d} \phi_{\mathrm{b}} / \mathrm{d} S_{\mathrm{b}}=-\mathrm{d} \phi_{\mathrm{s}} / \mathrm{d} S_{\mathrm{b}}=-\beta \phi_{\mathrm{b}} /\left(\rho_{\mathrm{b}}-\rho_{\mathrm{i}}\right)$ and thus, for $\rho_{\mathrm{i}}=917.0 \mathrm{~kg} \mathrm{~m}^{-3}$ and standard sea water with $S_{\mathrm{b}}=35$ and $\rho_{\mathrm{b}} \approx 1028 \mathrm{~kg} \mathrm{~m}^{-3}$, we find $\mathrm{d} \phi_{\mathrm{s}} / \mathrm{d} S_{\mathrm{b}} \approx-0.007 \phi_{\mathrm{b}}$ per unit salinity change. This method is thus much less sensitive to uncertainties in $S_{\mathrm{b}}$. However, as it is based on density differences, the bias from the air fraction, $\phi_{\mathrm{a}}$, is critical. Differentiating Eqn (15) yields $\mathrm{d} \phi_{\mathrm{s}} / \mathrm{d} \phi_{\mathrm{a}}=-\rho_{\mathrm{b}} /\left(\rho_{\mathrm{b}}-\rho_{\mathrm{i}}\right)$. For standard sea water this dependency is $\mathrm{d} \phi_{\mathrm{s}} / \mathrm{d} \phi_{\mathrm{a}} \approx-9$, implying that the presence of 0.01 fractional air volume leads to an overestimate in the solid volume fraction by 0.09 .

\section{(3) $\phi_{\mathrm{s}}$ based on grease density and bulk salinity}

Equation (19) utilizes both salt and mass conservation and allows us, based on observations of grease ice density, $\rho_{\mathrm{g}}$, and salinity, $S_{\mathrm{g}}$, alone, to determine the brine salinity, $S_{\mathrm{b}}$, and solid fraction, $\phi_{\mathrm{S}}$, of the ice. However, like method 2, this method would be strongly biased by very small amounts of air, as comparison of Eqn (15) with Eqn (20) indicates. It is found below that the overestimate in $\phi_{\mathrm{s}}$ due to the presence of air, $\phi_{\mathrm{a}}$, is even larger than for method 2, and typically $\mathrm{d} \phi_{\mathrm{s}} / \mathrm{d} \phi_{\mathrm{a}} \approx-12$.
(4) $\phi_{\mathrm{s}}$ based on measurements on drained samples

Equation (24) allows determination of the solid fraction, $\phi_{\mathrm{s}}$, and grease salinity, $S_{\mathrm{g}}$, also after the loss of brine, from the mass, $M_{\mathrm{g}}^{\prime}$, and salinity, $S_{\mathrm{g}}^{\prime}$, of the melted sample, provided that the original grease ice volume, $V_{g}$, is observed. Again, its uncertainty relates to the uncertainty of the volume and mass determinations. Also, similar to method 1, the sea-water approximation for the brine salinity implies an uncertainty of $\mathrm{d} \phi_{\mathrm{s}} / \mathrm{d} S_{\mathrm{b}} \approx-\left(M_{\mathrm{g}}^{\prime} / V_{\mathrm{g}} \rho_{\mathrm{i}}\right)\left(S_{\mathrm{g}}^{\prime} / S_{\mathrm{b}}^{2}\right)$ as a second error source. As $S_{\mathrm{g}}^{\prime}<S_{\mathrm{g}}$, and because $\left(M_{\mathrm{g}}^{\prime} / V_{\mathrm{g}} \rho_{\mathrm{i}}\right)<1$, this dependence is weaker than in method 1 . With $S_{\mathrm{b}}=35$ and the observation range $8<S_{\mathrm{g}}^{\prime}<26$, discussed later, this gives $\mathrm{d} \phi_{\mathrm{s}} / \mathrm{d} S_{\mathrm{b}}$ less than -0.007 to -0.021 per unit increase in $S_{\mathrm{b}}$. However, Eqn (24) contains $V_{\mathrm{g}}$ and $M_{\mathrm{g}}^{\prime}$ as further sources for observational errors. Because method 1 is much simpler, it is preferable if only the solid fraction of grease is to be determined. Yet method 4 gives additional information, such as the liquid and solid fractions of drained frazil crystals, $\phi_{\mathrm{b}}^{\prime}$ and $\phi_{\mathrm{s}}^{\prime}$. It is shown below that these are relevant for the validation of frazil modelling. It would thus be natural to sample the draining brine and measure $S_{\mathrm{b}}$. Finally, if $V_{\mathrm{g}}$ contains some air fraction, $\phi_{\mathrm{a}}$, prior to drainage, this will have a similar effect to that in method 1 . The corresponding correction for $\phi_{\mathrm{s}}$ is obtained by subtracting $\phi_{\mathrm{a}}$ from the righthand side of Eqn (24) and replacing $V_{\mathrm{g}}$ by $V_{\mathrm{g}}\left(1-\phi_{\mathrm{a}}\right)$, which gives a slightly lower reduction of $\phi_{\mathrm{s}}$ than by $\phi_{\mathrm{a}}$.

\section{Summary}

To summarize, one may derive the solid fraction from two or three observed variables, using a combination of mass-, volume- and salt-conservation equations with their respective advantages and disadvantages:

1. Observing $S_{\mathrm{g}}$ and $S_{\mathrm{b}}\left(S_{\mathrm{w}}\right) \Rightarrow$ requires either brine separation or application of the sea-water approximation for the brine salinity $\left(S_{\mathrm{b}}=S_{\mathrm{w}}\right)$. A 1 psu higher brine salinity introduces an underestimate in $\phi_{\mathrm{s}}$ of typically $0.02-0.025$, which may in turn be reduced by the fraction of air in the grease ice.

2. Observing $\rho_{\mathrm{g}}$ and $S_{\mathrm{b}}\left(S_{\mathrm{w}}\right) \Rightarrow$ leads to a small error from the $S_{\mathrm{b}}=S_{\mathrm{w}}$ sea-water approximation, but a large potential error due to air content (0.09 in $\phi_{\mathrm{s}}$ due to 0.01 in $\phi_{\mathrm{a}}$ ).

3. Observing $\rho_{\mathrm{g}}$ and $S_{\mathrm{g}} \Rightarrow$ is based on bulk grease measurements alone, but also implies a large potential error due to air content.

4. Observing $V_{\mathrm{g}}, S_{\mathrm{g}}^{\prime}, M_{\mathrm{g}}^{\prime}, S_{\mathrm{b}}\left(S_{\mathrm{w}}\right) \Rightarrow$ requires crystal separation and the most measurement effort. It gives a reduced error from the $S_{\mathrm{b}}=S_{\mathrm{w}}$ approximation, but is prone to uncertainties in $V_{\mathrm{g}}$ and $M_{\mathrm{g}}^{\prime}$.

\section{OBSERVATIONS}

In the following, we review existing observations of grease ice in terms of the above methods.

\section{(1) $\phi_{s}$ based on grease salinity}

Somewhat surprisingly, in only a few studies has the bulk salinity, $S_{g}$, of grease ice been reported as a directly observed parameter. Equation (9) has thus been rarely applied. Onstott and others (1998) reported a salinity of $S_{\mathrm{g}}=29$ for the first grease ice forming under wave conditions in a tank of water salinity $S_{w}=30$, and a value of 20 for several-hoursold grease and slush. Assuming a precision of \pm 0.5 for the 
grease ice measurements, Eqn (9) implies $0.01<\phi_{\mathrm{s}}<0.06$ and $0.34<\phi_{\mathrm{s}}<0.38$ for young and old grease ice, respectively. Low solid fractions of $0.05<\phi_{\mathrm{s}}<0.10$ were also reported by Tyshko and Cherepanov (1998) for laboratory experiments, where frazil ice was grown with rather high supercooling (up to $3 \mathrm{~K}$ ). Gradinger and Ikävalko (1998) determined, for new grease ice samples obtained from a ship along the marginal ice zone in the Greenland Sea, a median $S_{\mathrm{g}}=23.3$ (range 23-26), while the water salinity was 32.4 . They also measured water temperatures and used equations of Frankenstein and Garner (1967), based on thermodynamic equilibrium and approximate scaling of brine salinity from the (freezing) temperature, to calculate a median solid fraction of 0.38 (range 0.25-0.44). We note that the approximations of Frankenstein and Garner (1967) overestimate the solid fraction in the encountered temperature and brine salinity regime. Comparing them, using Eqn (9), with the freezing point of sea water (e.g. Fofonoff and Millard, 1983; Maus, 2007), suggests a lower median $\phi_{\mathrm{s}} \approx 0.35$ and upper bound, 0.42, for the study by Gradinger and Ikävalko (1998). Smedsrud and Skogseth (2006) report bulk grease salinities between 22 and 28 for grease observations in Svalbard fjords which, with water salinity $S_{\mathrm{w}} \approx 34.5$, corresponds to $0.21<\phi_{\mathrm{s}}<0.39$ using Eqn (9). Finally, one of us (S. Maus, unpublished data, 1999) measured $24<S_{\mathrm{g}}<32$ for mostly young frazil and grease samples of different ages during fieldwork on Svalbard, with water salinities in the range $34.2 \pm 0.4$, which gives the range $0.07<\phi_{\mathrm{s}}<0.30$. The latter observations, for which density measurements were also obtained, are further discussed below.

\section{(2) $\phi_{s}$ based on grease and brine densities}

A number of authors have applied Eqn (13) to estimate $\phi_{\mathrm{s}}$ from volume measurements and the weight of drained ice. As no correction was applied for the liquid remaining after drainage, the following results overestimate the true $\phi_{\mathrm{s}}$. We first note two investigations of freshwater frazil: Andersson and Daly (1992) reported $0.33 \pm 0.13(n=20)$ for a laboratory study, while frazil deposits collected by White and Lawson (1992) in the field gave a wider range $0.23<$ $\phi_{\mathrm{s}}<0.65$ and a higher average of 0.48 . For sea water, Voropayev and others (1995) report a value of $0.25 \pm 0.03$ obtained during a tank experiment. A most typical value of 0.3 has been reported for frazil ice in Antarctic coastal waters (Cherepanov and Kozlovskii, 1973), while Doble and others (2003) and Doble (2007) quote a typical solid fraction of 0.4 for frazil slicks in the Weddell Sea. Martin and Kauffman (1981) reported, for a laboratory study of frazil growth in a small wave-tank filled with $\mathrm{NaCl}$ saltwater, the range 0.18 0.44 , with the maxima and minima referring to the thickest and thinnest frazil crystal accumulation. A range of $0.35-$ 0.40 was noted in an earlier laboratory study by Martin and others (1977), for similar $\sim 10 \mathrm{~cm}$ thick ice. Reimnitz and others (1993) mention a high value of 0.5 for the upper $5 \mathrm{~cm}$ of a $30 \mathrm{~cm}$ thick slush column that had accumulated from rising frazil crystals which formed at the bottom of a cylindrical tank. The latter authors noted that the frazil compacted while increasing in thickness, and also measured the solid fraction of the first $4 \mathrm{~cm}$ of accumulating frazil in the range $0.15-0.32$.

As discussed above, all these density-based measurements must be viewed as upper bounds for $\phi_{\mathrm{s}}$, because of an unknown amount of liquid water/sea water on the surface

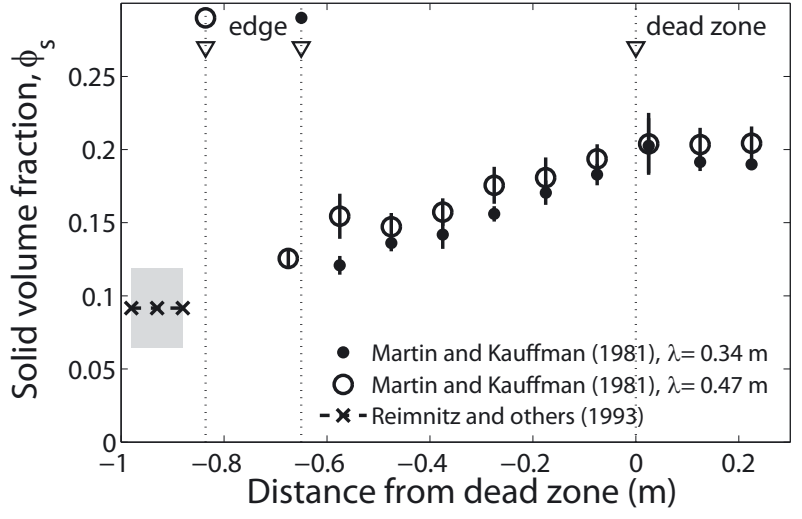

Fig. 1. Solid volume fraction of grease ice formed under waves in a laboratory tank, based on data from Martin and Kauffman (1981), given at different distances from the ice edge. The volume of drained frazil crystals from their figures 17 and 18 was corrected for liquid water using Eqn (8). The results for two wavelengths were then averaged from the ice 'edge' to the 'dead zone', where waves are mostly damped. Note that for the longer wavelength $(\lambda=0.47 \mathrm{~m})$ this distance is larger. The range based on data from Reimnitz and others (1993) for very young frazil risen to the surface of a cylindrical tank is shown, for comparison, as crosses on the left.

or in the pores of the weighted ice crystals. However, two of the above studies (Martin and Kauffman, 1981; Reimnitz and others, 1993) also measured and reported the salinity, $S_{\mathrm{g}}^{\prime}$, of drained ice. This term allows us to correct the solid fraction via Eqn (9). In addition, Reimnitz and others (1993) reported the brine salinities (their fig. 4) being 0.4-1.9 higher than the tank saltwater values. Estimates from their data are thus not affected by the uncertainties introduced by the assumption that sea water equals brine. When the correction for the solid fraction is applied, we obtain a range $0.07<\phi_{\mathrm{s}}<0.12$ for their experiments, with an average of 0.09. These observations are indicated as crosses in the lower left corner of Figure 1.

Martin and Kauffman (1981), the second source for which it is possible to apply a correction to solid fraction results, mentioned an average salinity of $S_{\mathrm{g}}^{\prime}=11.8 \pm 2.1$ which, in connection with the tank salinity of 38.4 , yields a solid ice fraction of $\phi_{\mathrm{s}}^{\prime} \approx 0.72$, for drained frazil. They further provided information about the horizontal distribution of the solid fraction along their $2 \mathrm{~m}$ long wave tank (their figs 17 and 18), that we partly reproduce, scaled by the correction factor, in Figure 1. (The given solid fractions, including brine, are multiplied by the average solid fraction, 0.72 , of the frazil. In addition, the solid and melted ice densities in eqns (14) and (15) of Martin and Kauffman (1981) needed to be changed to allow comparison. Evaluating our Eqn (13), we found this difference corresponds to an additional underestimate of $\phi_{\mathrm{s}}$ by 0.007 , which we also added.) Figure 1 shows (as solid and open circles) solid fractions averaged over four ice-growth experiments, each for two different wavelengths, $\lambda=0.34$ and $0.47 \mathrm{~m}$, yet with slightly different wave amplitudes. The lowest solid fractions appear on the lefthand side, at negative numbers of the $x$-axis, where the frazil edge is situated. The frazil edge was defined by Martin and Kauffman (1981) as the distance from the 'dead zone' where the waves were almost completely damped. They showed that this damping took place, in that the wave amplitude, $a_{0}$, decayed linearly from the frazil edge to the dead zone, giving a decay distance of $X \approx 4 /\left(k^{2} a_{0}\right)$, where $k=2 \pi / \lambda$ 


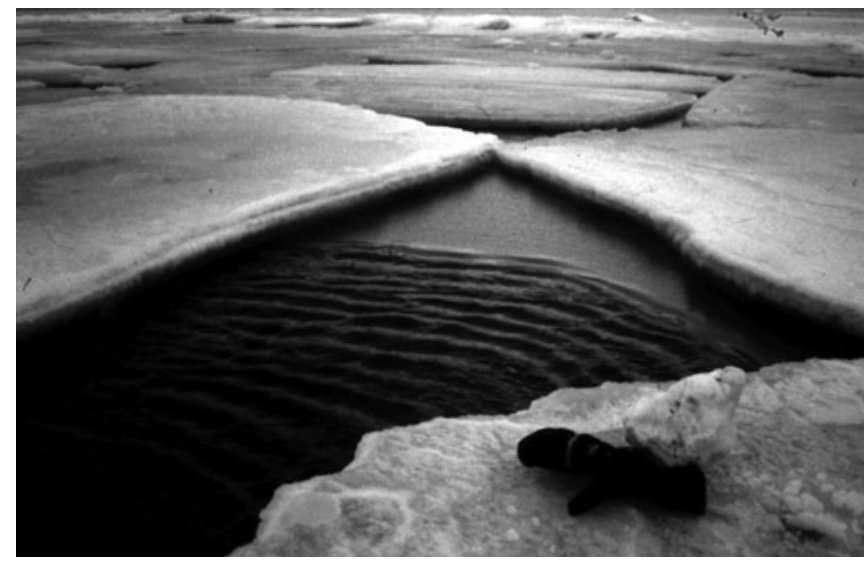

Fig. 2. Grease ice forming in the presence of short waves in a small, easily accessible, lead between grounded floes. Note the damping of waves in the grease regime. Water depth $\sim 50 \mathrm{~cm}$, grease thickness $\sim 3 \mathrm{~cm}$. Adventfjorden, Svalbard, February 1999. (Photograph S. Maus.)

is the wavenumber. The decay distance is noted as 'edge' in Figure 1 and has been computed from the average $k a_{0}$ for the wavelength subsets. It is close to twice the wavelength.

The horizontal distributions of Martin and Kauffman (1981) thus show $\phi_{\mathrm{s}}$ in the range $0.13-0.17$ near the edge, where the specific grease ice layer thickness was only a few centimetres, increasing to values of $0.18-0.23$ within the dead zone, where the grease layer was $\sim 10 \mathrm{~cm}$ thick. Another noteworthy finding is that, when the observations are extrapolated by eye to their respective 'edges', where the frazil is youngest, one obtains minimum values of $0.10<$ $\phi_{\mathrm{s}}<0.12$, close to the values of very young frazil obtained by Reimnitz and others (1993).

\section{(3) $\phi_{s}$ based on grease salinity and density}

This method allows us to compute the brine salinity and solid fraction of grease ice from observations of its bulk salinity, $S_{\mathrm{g}}$, and density, $\rho_{\mathrm{g}}$. We are not aware of previous studies that have applied this approach, and present data from fieldwork performed during February and March 1999 in Adventbay, Longyearbyen, Svalbard, 200-300 m from the university building (UNIS). Due to the tidal cycle, small leads, mostly 2-20 m, opened regularly in shallow water (0.5-10 m depth) close to the shore within an ice cover $10-50 \mathrm{~cm}$ thick. Along the coast a 1-2 $\mathrm{m}$ wide open-water strip opened and closed regularly. In shallow areas many leads were easily accessible from the land via grounded floes, with grease ice forming under the presence of short wind-generated waves (Fig. 2). The present observations were obtained during moderate winds $\left(4-12 \mathrm{~m} \mathrm{~s}^{-1}\right)$ and air temperatures $\left(-4\right.$ to $\left.-14^{\circ} \mathrm{C}\right)$ in leads of different sizes, as noted in Figure 3. In all leads the grease was 3-6 cm thick and still accumulating. In the cases noted as shuga, the grease appeared in the form of small pans that still had a slush consistency. Three observations (shown as stars) represent snow/slush from a stage when the ice cover had disappeared due to a storm, followed by 2 days of snow precipitation. Under weak $\left(4-6 \mathrm{~m} \mathrm{~s}^{-1}\right)$ onshore winds directed across the $3 \mathrm{~km}$ wide fjord, a slush ice cover $20 \mathrm{~cm}$ thick had formed and extended offshore to a distance of $50-100 \mathrm{~m}$. We proceeded as follows. In the field, ice samples were collected by scooping grease ice from the upper $1-3 \mathrm{~cm}$, using a conventional soup-dipper. Glass bottles $(\sim 1 \mathrm{~L})$ of known volume (within $0.5 \mathrm{~mL}$ ) and dry weight (within $0.1 \mathrm{~g}$ ) were completely filled with grease and weighed in the nearby laboratory to obtain the grease density with an estimated uncertainty of $2 \mathrm{~g} \mathrm{~kg}^{-3}$. Electrolytic conductivity and temperature of the melted grease were measured with a WTW LF 320 hand-held instrument which has a nominal relative accuracy of $0.5 \%$ (or $\sim 0.2$ in terms of present typical salinities, 25-35). The instrument was calibrated through comparison with conductivities obtained with a Guildline Portasal 8410 salinometer (accuracy better than 0.01 for salinity). The grease ice salinity determinations, $S_{\mathrm{g}}$, are thought to have an accuracy better than 0.4 . To avoid the inclusion of frazil crystals, water samples were obtained at the upwind edge of the leads, and also during conditions of no grease formation. They varied typically by \pm 0.4 during 2 months of fieldwork.
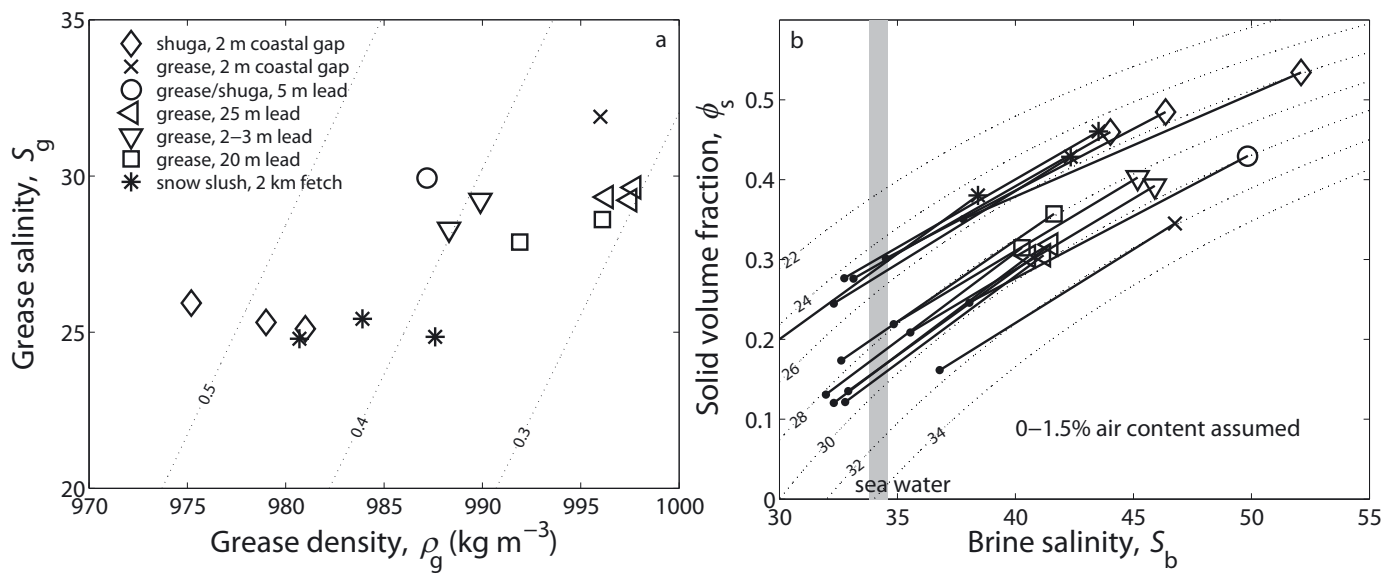

Fig. 3. Results from grease ice sampling in Adventfjorden. Different symbols represent the different sampling locations described in the text. (a) Actual measurements of grease salinity, $S_{\mathrm{g}}$, vs grease density, $\rho_{\mathrm{g}}$, with contours of solid fraction, $\phi_{\mathrm{S}}$, based on Eqns (18) and (19) shown as dotted curves. (b) Derived $\phi_{\mathrm{s}}$ and $S_{\mathrm{b}}$ on the basis of measurements shown in (a), applying Eqns (18) and (19), with contours of grease salinity, $S_{g}$, shown as dotted curves. While the symbols present calculations assuming no air content, the arrows indicate the change in derived values when $1.5 \%$ air porosity is assumed. Grease ice salinity contours are drawn from 22 to 34 , while the range of observed sea-water salinities is shown within the grey shading. 
The observations of grease salinity, $S_{\mathrm{g}}$, and density, $\rho_{\mathrm{g}}$, are presented in Figure $3 \mathrm{a}$, with contours of solid fraction, $\phi_{\mathrm{s}}$, based on Eqns (18) and (19) shown as dotted curves. All observations fall in the range $24<S_{\mathrm{g}}<32$, the snow/slush having the lowest bulk salinity. The derived solid fractions obtained in this way are in the range 0.3-0.5. Applying Eqns (18) and (19) we further obtained the brine salinity, $S_{\mathrm{b}}$, of the samples which are plotted against the derived solid fraction, $\phi_{\mathrm{s}}$, in Figure $3 \mathrm{~b}$. In this figure, the contours represent the grease ice bulk salinity dependence, based on the two properties given in Eqn (25). Comparison of the derived brine salinities plotted in Figure $3 a$ and $b$ with the grey-shaded vertical bar in Figure $3 b$, which represents the observed range of sea-water salinity $34.2 \pm 0.4$, typical for Svalbard fjords during winter (e.g. Maus and others, 2011), indicates that these exceed the sea-water salinity by 5-20. Such values are, compared to all earlier investigations, unrealistically large. Also, during the fieldwork we obtained temperature observations of the sea water and grease layer with a thermometer of limited precision $(0.1 \mathrm{~K})$. These gave either a $0.1 \mathrm{~K}$ lower grease ice temperature or no difference compared to the underlying sea water, while only for the surface of partly solidified shuga did we obtain values $0.4-0.5 \mathrm{~K}$ below the sea-water freezing point. Hence, also due to the observed temperatures, assuming thermodynamic equilibrium, it is unlikely that the brine salinity exceeded the sea-water value by more than 2 for our samples.

As discussed earlier, a relatively small air porosity has a strong influence on the density-based estimate (method 2) and the correction for air content leads to lower $S_{\mathrm{b}}$ and $\phi_{\mathrm{s}}$. Figure $3 \mathrm{~b}$ shows the results based on Eqn (20) modified for air porosity, assuming $\phi_{\mathrm{a}}=0.015$. The change is indicated by the solid lines, with dots representing an air porosity of 0.015 . These corrected calculations give brine salinities close to the expected sea-water values. While we are not aware of air porosity observations for grease ice, the assumed $\phi_{\mathrm{a}}$ upper limit is roughly consistent with air porosities documented for young laboratory and field samples of solid ice, with most values in the range $0.005<\phi_{\mathrm{a}}<0.015$ (Nakawo, 1983; Tison and others, 2002). The large range in $S_{\mathrm{b}}$ and $\phi_{\mathrm{s}}$ obtained for the range $0<\phi_{\mathrm{a}}<0.015$ in Figure $3 \mathrm{~b}$, then demonstrates that the uncertainty connected with air inclusions precludes a proper determination of the brine salinity, $S_{\mathrm{b}}$, from this method (3). However, note that the problem can be inverted using additional observations of the brine salinity, $S_{\mathrm{b}}$, or an estimate of the latter from the sea-water salinity. For our observations, assuming a typical sea-water salinity of 34.2 for the brine, we then determine air volumes $0.007<\phi_{\mathrm{a}}<0.025$, with a mean of $0.016 \pm 0.005$. By the same arguments it is likely that the 'correct' solid fractions are obtained when inserting a brine salinity close to the sea-water value into Eqn (20). In Figure $3 \mathrm{~b}$ the corresponding $\phi_{\mathrm{s}}$ values can be graphically obtained by following the grease salinity contour, on which the observations lie, to the grey vertical shading. This gives the range $0.07<\phi_{\mathrm{s}}<0.30$, mentioned in the previous subsection for this set of data.

\section{(4) $\phi_{\mathrm{s}}$ from drained samples}

Several investigators have reported the salinity of partly drained frazil ice samples. Doble (2007) reported $S_{\mathrm{g}}^{\prime}$ for shipbased field observations in the Weddell Sea in the range 819 , with a tendency to decrease with distance from the ice edge. Wadhams and Wilkinson (1999) reported, for frazil and

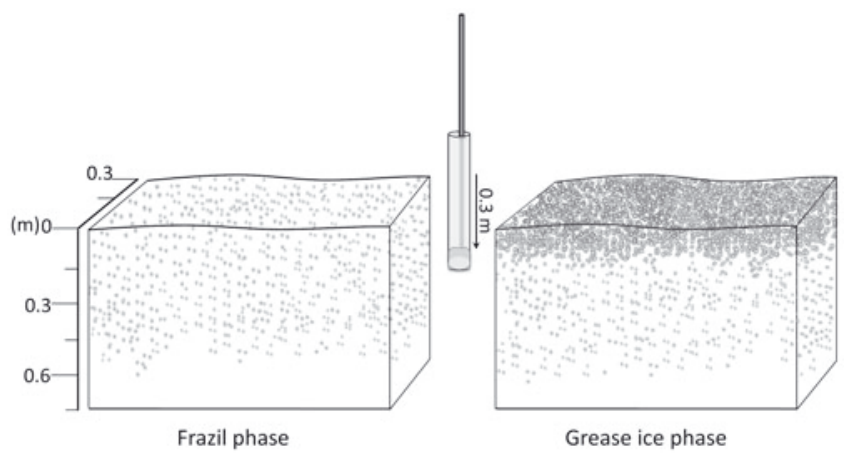

Fig. 4. Sketch showing the tank experiments to obtain grease ice samples described by De la Rosa and Maus (2011) and De la Rosa and others (2011). A Plexiglas cylinder was submerged $30-40 \mathrm{~cm}$ through the grease layer once it appeared (right) and closed by a lid. Out of the water, the grease thickness was read from a scale on the cylinder. This procedure also samples part of the water column (right) and very freshly settled frazil.

slush collected between pancakes in the Greenland Sea, a range of 5-22, while observations compiled by Wilkinson (2005) for several cruises in the Greenland Sea spanned the range $8-24$. The latter author also reported observations from tank experiments with $\mathrm{NaCl}$ sea-water model solutions in the range $16<S_{\mathrm{g}}^{\prime}<26$. Smedsrud and Skogseth (2006) reported values in the range 16-28 for 3-30 cm thick grease ice sampled in fjords around Svalbard. Reimnitz and others (1993) blew air through the frazil to remove the brine and obtained residual salinities between 12 and 20, while Martin and Kauffman (1981) found $11.8 \pm 2.1$ in residual ice growing from $\mathrm{NaCl}$ solution of $S_{\mathrm{w}} \approx 38.4$, which, scaled to standard sea water $(S=35)$, corresponds to 10.9 .

While the latter two studies also reported bulk salinities, and were discussed above, in terms of method 2, in most other studies the mass of lost brine or the volume of the original sample was not observed, and the solid fraction and salinity of in situ grease remained undetermined. Smedsrud and Skogseth (2006) computed solid fractions from their eqn (6), as $V_{\mathrm{g}}^{\prime} / V_{\mathrm{g}}\left[1-\left(S_{\mathrm{g}}^{\prime} / S_{\mathrm{b}}\right)\right]$, which is inaccurate compared to our Eqn (25), due to an incorrect salt conservation in the derivation (their eqn (3) lacks densities). If this is corrected, then their solid fraction range of $0.16-0.32$ increases by $10 \%$, becoming 0.18-0.35. Smedsrud and Skogseth (2006) did not calculate the in situ grease ice salinities from the drained ice data either. Using their reported water salinity of 34.5 we obtain, with Eqn (25), a range of $23<S_{\text {g }}<29$.

We have obtained in a recent study a large dataset of grease ice grown under wave conditions for four experiments (E1-E4) within two parallel tanks (each $3 \mathrm{~m}$ wide and $15 \mathrm{~m}$ long). All experiments lasted for $\sim 2$ days, during which a grease ice cover of $5-10 \mathrm{~cm}$ thickness evolved. Details of the experiments, that varied slightly in terms of wave forcing, are provided by De la Rosa and Maus (2011) and De la Rosa and others (2011). Grease ice samples were obtained from a movable bridge at fixed positions along the $15 \mathrm{~m}$ long tank axis. From the bridge a $60 \mathrm{~cm}$ long hollow Plexiglas cylinder was submerged typically $30-40 \mathrm{~cm}$ from the surface and sealed at the bottom to sample grease ice of $1-10 \mathrm{~cm}$ layer thickness (Fig. 4). First the volume, $V_{g}$, of undrained grease ice was determined from thickness readings of the grease that filled the cylinder. After this, the sample was drained, sieved and its mass, $M_{\mathrm{g}}^{\prime}$, was measured. The brine that 

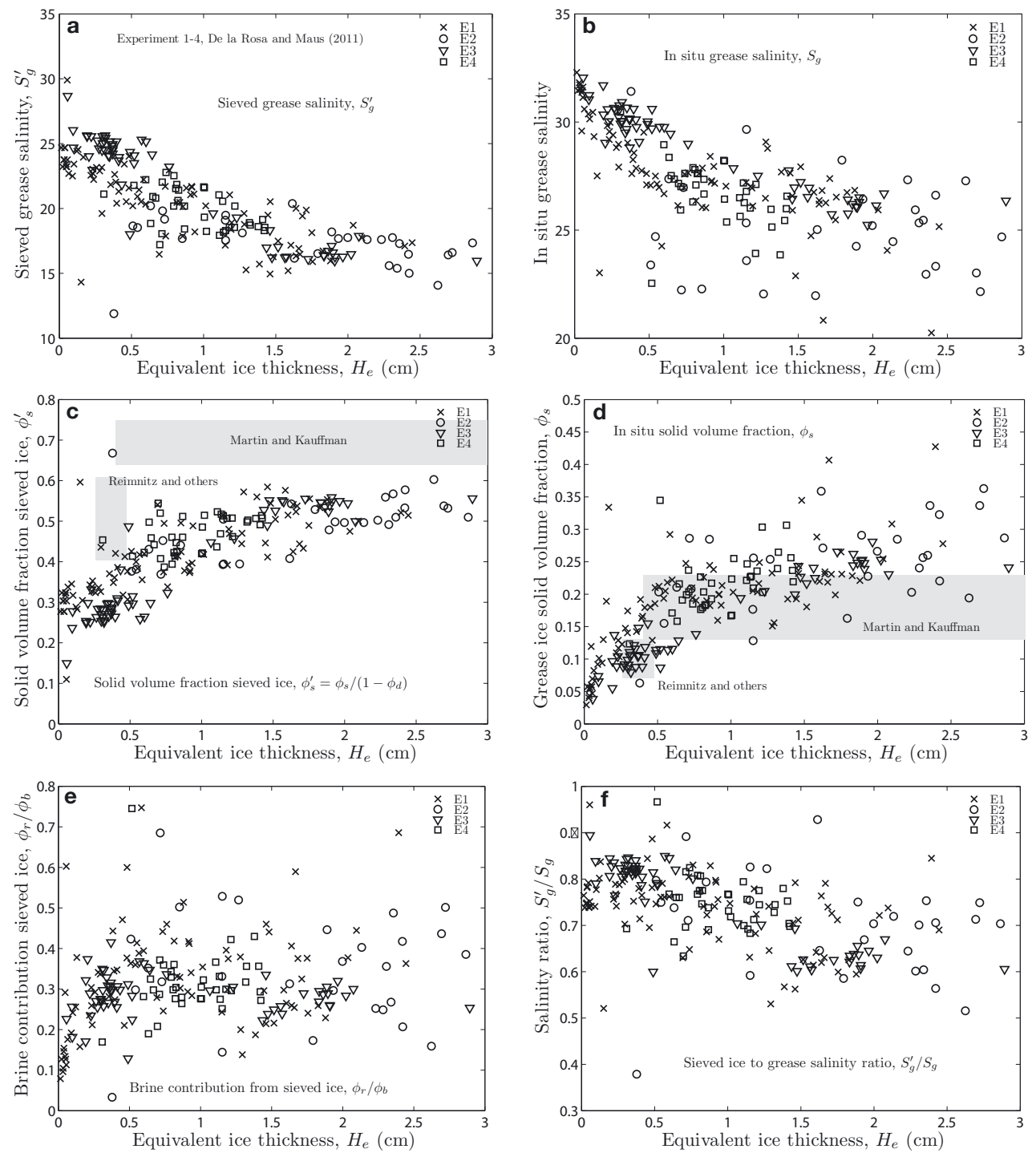

Fig. 5. Grease ice properties obtained in tank experiments under wave conditions (De la Rosa and Maus, 2011): (a) observed salinity, $S_{g}^{\prime}$, of sieved ice; (b) derived in situ or bulk grease ice salinity, $S_{\mathrm{g}}$; (c) derived solid volume fraction, $\phi_{\mathrm{s}}^{\prime}$, of sieved ice (the upper shading indicates the typical range from laboratory data reported by Martin and Kauffman (1981), the left shading data from Reimnitz and others (1993); both are indicated for the equivalent ice thickness in the studies); (d) derived solid volume fraction, $\phi_{\mathrm{S}}$, of in situ grease ice (again with shadings indicating the typical range estimated from laboratory data reported by Martin and Kauffman (1981) and Reimnitz and others (1993)); (e) contribution of sieved ice brine volume to total brine volume, $\phi_{\mathrm{r}} / \phi_{\mathrm{b}}$ and (f) ratio of sieved ice salinity to bulk grease salinity, $S_{\mathrm{g}}^{\prime} / S_{\mathrm{g}}$.

drained from the ice was not collected. The salinity, $S_{g}^{\prime}$, of the drained ice crystals was then determined from electrolytic conductivity measurements after melting. Time series of tank water salinity, $S_{\mathrm{W}}$, and temperature were also available to derive the solid fraction, $\phi_{\mathrm{s}}$, and bulk salinity, $S_{\mathrm{g}}$, using Eqns (24) and (25). Disregarding the uncertainty due to the $S_{\mathrm{b}}=S_{\mathrm{w}}$ assumption, the uncertainty in $\phi_{\mathrm{s}}$ is mostly related to the accuracy $(0.3 \mathrm{~cm})$ by which the ice thickness, $H$ (and thus the volume, $V_{\mathrm{g}}$ ), could be measured. It decreased from $30 \%$ for $1 \mathrm{~cm}$ thick ice to $<5 \%$ when the ice reached $10 \mathrm{~cm}$ thickness. While pancake samples were also obtained (De la Rosa and Maus, 2011), in the present study we only discuss grease samples, i.e. any samples that were partially solid or stiff are not considered. With increasing time and thickness the grease covered less of the tank surface, and at later stages grease samples were obtained between pancakes.

The results are summarized in Figure 5, where we plot several grease ice properties against the equivalent ice thickness, $H_{\mathrm{e}}$. The latter is defined as the product of the solid fraction, $\phi_{\mathrm{s}}$, and sampled grease layer thickness, $H$, and thus corresponds to the thickness of pure ice. Experiments E1E4 were performed at different wavelengths and amplitudes and are thus distinguished here. However, as discussed by De la Rosa and Maus (2011), the experiments did not differ significantly in terms of grease ice salinity and solid fractions. The equivalent thickness in the experiments reached typically $2-3 \mathrm{~cm}$ during the course of 1 day, after which grease sampling was not continued, because the grease increasingly froze-up into pancakes. The heat loss from the tank in relation to its surface area was relatively constant, corresponding to $Q=60-80 \mathrm{~W} \mathrm{~m}^{-2}$, such that $1 \mathrm{~cm}$ of $H_{\mathrm{e}}$ formed during $t \approx 12$ hours $\left(H_{\mathrm{e}} \approx Q t /\left(L_{\mathrm{f}} \rho_{\mathrm{i}}\right)\right.$, where $L_{\mathrm{f}}=330 \mathrm{~kJ} \mathrm{~kg}^{-1}$ is the latent heat of fusion). Hence, the thickness shown on the $x$-axis may also be interpreted as being proportional to the time for the frazil to accumulate, or approximately half its average age. 

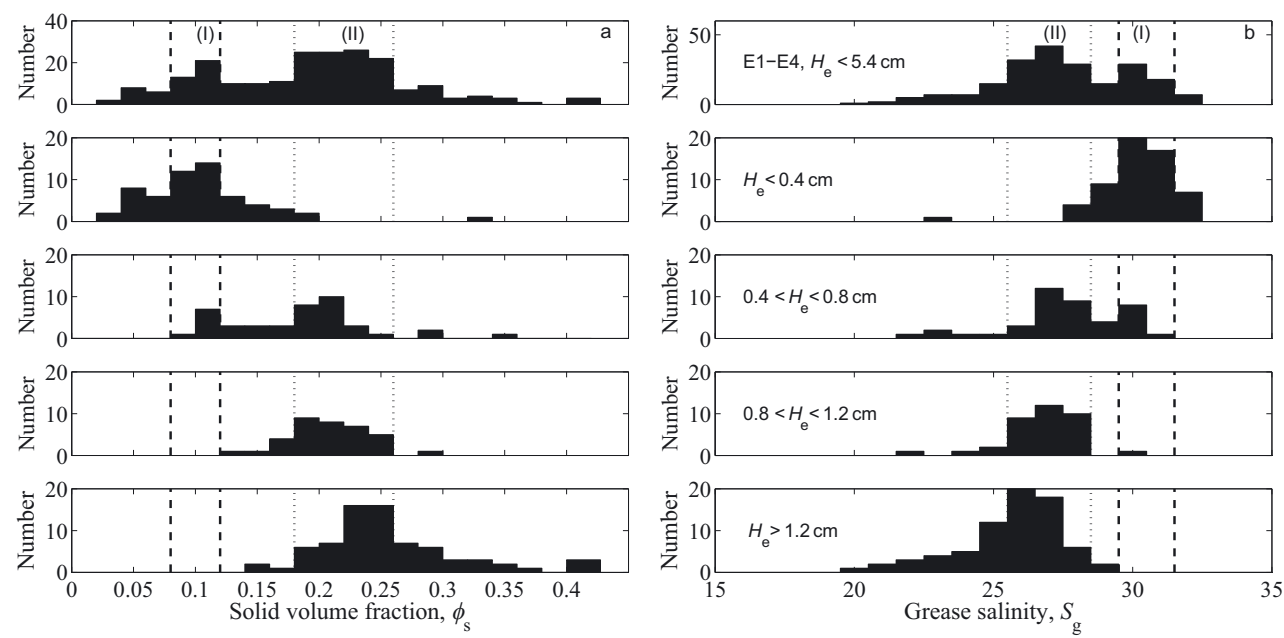

Fig. 6. Grease ice solid volume fractions $\phi_{\mathrm{s}}$ and salinities $S_{\mathrm{g}}$ versus equivalent ice thickness and time. Data have been grouped from Figure 5 into $0-0.4 \mathrm{~cm}(t<5$ hours), $0.4-0.8 \mathrm{~cm}$ ( $5<t<10$ hours), $0.8-1.2 \mathrm{~cm}(10<t<15$ hours) and $>1.2 \mathrm{~cm}(t>15$ hours) equivalent ice thickness, from top to bottom, while the upper histogram shows all observations. The two regimes indicated with (I), between dashed vertical lines and (II), between dotted vertical lines, correspond to the modes of compaction discussed in the text.

We first note that both the observed drained ice salinity, $S_{\mathrm{g}}^{\prime}$, in Figure $5 \mathrm{a}$, and the derived in situ ice salinity, $S_{\mathrm{g}}$, in Figure $5 b$ decrease with thickness, with respective overall ranges of $12<S_{\mathrm{g}}^{\prime}<30$ and $20<S_{\mathrm{g}}<33$. The corresponding solid fraction, $\phi_{\mathrm{s}}$, increases from initial low values of $0.03-0.06$ to values between 0.25 and 0.35 , while only a few values appear above this limit (Fig. $5 d$ ). While the data fall within the regimes of drained ice crystal salinities, $S_{\mathrm{g}}^{\prime}$, as well as undrained $S_{\mathrm{g}}$ of grease obtained in other studies, the figure demonstrates, for the first time, their evolution with time/thickening of the ice. Also the solid fractions in Figure $5 d$, disregarding the very young and thin grease below $H_{\mathrm{e}} \approx 0.5 \mathrm{~cm}$, are consistent with the data shown in Figures 1 and 3. Observational ranges from Martin and Kauffman (1981) and Reimnitz and others (1993) (Fig. 1) are also shown in Figure 5d. Note that the data from Martin and Kauffman (1981) in Figure 1 indicate a trend of increasing $\phi_{\mathrm{s}}$ away from the ice, and hence with increasing $H_{\mathrm{e}}$, but that, due to a lack in reported $H_{\mathrm{e}}$, only the overall range is indicated in Figure $5 \mathrm{~d}$. In Figure $5 \mathrm{c}$ we also show the solid ice volume fraction of the sieved ice crystals, which we recall is given as $\phi_{\mathrm{s}}^{\prime}=\phi_{\mathrm{s}} /\left(1-\phi_{\mathrm{d}}\right)$, where $\phi_{\mathrm{d}}$ is the volume fraction of the bulk sample lost by drainage and sieving. Our values are lower than the average reported in the laboratory experiments of Martin and Kauffman (1981), discussed above, indicated as the horizontal shaded area. They are comparable to the values found for young drained laboratory frazil studied by Reimnitz and others (1993). However, if we consider the typical equivalent ice thickness in the latter study, indicated by the location of the grey shading, the present solid fraction of frazil crystals is also lower. Note that Martin and Kauffman (1981) only reported the range of $\phi_{s}^{\prime}$, and not the dependence on thickness or distance from the ice edge, as for $\phi_{\mathrm{s}}$ in Figure 1.

An interesting aspect, in terms of the salt budget of grease ice, is the fraction of brine contained in the sieved ice, with respect to the overall brine content. This is the ratio $\phi_{\mathrm{r}} / \phi_{\mathrm{b}}$ shown in Figure 5e. It increases initially with thickness, but appears to become independent of equivalent thickness above $0.1-0.2 \mathrm{~cm}$, for which we computed $0.33 \pm 0.11$.
Hence, one-third of the brine in the grease ice was typically trapped by solid ice crystals and could not be sieved off under unit gravity and minute timescales. With respect to the many studies that have only measured drained ice salinities, in Figure $5 f$ we plot the ratio, $S_{g}^{\prime} / S_{g}$, of drained to bulk grease salinity. This ratio is not constant but decreases with the equivalent ice thickness. The scatter is large, and an extrapolation of the data does not seem appropriate. Hence, $S_{\mathrm{g}}^{\prime}$ alone does not appear to have a large potential to allow the prediction of $S_{\mathrm{g}}$, the in situ salinity of grease ice. However, drained frazil crystal salinities are $10-50 \%$ smaller than grease ice salinities, with a larger relative difference the older the ice and the lower its salinity.

To further illustrate the evolution with thickness and time, we group the observations of solid fraction and salinity from Figure $5 b$ and $d$ into intervals of $0-0.4,0.4-0.8,0.8-1.2$ and $>1.2 \mathrm{~cm}$ equivalent ice thickness which, for the heat fluxes in the experiments, correspond approximately to time intervals of $0-5,5-10,10-15$ and $>15$ hours. Figure 6 shows the histograms for the respective thickness regimes and the overall histogram of all observations. Two modes are visible in the data, for both salinity, $S_{g}$, and solid fraction, $\phi_{\mathrm{s}}$, and have been indicated by vertical lines. First, there is a high-salinity $\left(29.5<S_{\mathrm{g}}<31.5\right)$ and low-solid-fraction $\left(0.08<\phi_{\mathrm{s}}<0.12\right)$ mode that appears dominant during the first 5 hours and disappears after 10 hours (mode I). Second, there is a broader plateau-like maximum (mode II) in the histogram spanning the ranges $26.5<S_{\mathrm{g}}<29.5$ and $0.18<\phi_{\mathrm{s}}<0.26$. The broadness of the latter range is, as shown in Figure 5, the consequence of the time evolution of the ice, which causes a shift from higher to lower salinities (lower to higher solid fractions) with time. At early times (and thickness) a few solid-fraction values are present above 0.3 , but far from the low-solid-fraction mode. At later times (and low thickness), there appear to be more solid fractions between 0.3 and 0.4 , but most observations fall below this regime of maximum values. Within our limited resolution and the small number of samples in each group, none of the distributions may be classified as normal (this hypothesis was rejected with a Lilliefors test with significance level 
$p=0.2$ ). The relatively sharp drop in the regime $0.25-0.30$ indicates some threshold behaviour is analysed below in the discussion in connection with a simple model.

\section{DISCUSSION}

Before we proceed with a more detailed analysis of the data in Figures 5 and 6, we summarize the overview and reanalysis of observational studies of grease ice, in terms of bulk salinity and solid fraction, as follows.

New data presented in this work (Figs 3 and 5) and observations from earlier studies (Martin and Kauffman, 1981; Reimnitz and others, 1993; Tyshko and Cherepanov, 1998) indicate that very young grease ice a few centimetres thick is found to have solid fractions in the range $0.07-0.12$.

The typical solid fraction of grease ice obtained in the field seldom exceeds values of $0.30-0.35$ (this work and Cherepanov and Kozlovskii, 1973; Gradinger and Ikävalko, 1998; Onstott and others, 1998; Smedsrud and Skogseth, 2006).

The highest values of grease ice solid fractions appear to fall in the range 0.4-0.45 (this work and Gradinger and Ikävalko, 1998).

Our data in Figure $5 d$ highlight the time and thickness evolution of the solid fraction, $\phi_{s}$, of which no comparable observations exist to date (while Fig. 5b shows the corresponding grease salinity change). However, as we have indicated in Figure $5 d$, the observations of $\phi_{\text {s }}$ of very young grease reported by Reimnitz and others (1993) do agree with our young frazil. As shown in Figure 1, for the laboratory experiments of Martin and Kauffman (1981) the solid fraction increased with distance from edge from $\sim 0.13$ to 0.23 . From the information given by the latter authors this roughly corresponds to an increase in equivalent ice thickness, $H_{\mathrm{e}}$, from 0.4 to $3 \mathrm{~cm}$, similar to our observational range, over which our observations increase from typically $0.08-0.12$ to 0.22-0.26. We indicate these two modes I and II in Figure 6. Our data at lowest equivalent thickness $\left(H_{\mathrm{e}}<0.2 \mathrm{~cm}\right)$ in Figures $5 \mathrm{~d}$ and 6 indicate very low solid fractions, $0.03<$ $\phi_{\mathrm{s}}<0.06$, that have not been documented in any previous study. It is notable that Figure $5 e$ indicates that in this regime the contribution from the (sieved) ice crystals to the brine volume of the unsieved grease ice sample, $\phi_{\mathrm{r}}^{\prime} / \phi_{\mathrm{b}}$, takes the lowest values. Also in the solid-fraction distribution at low thickness (second histogram from top in Fig. 6a) one might suspect a third mode at low solid fractions.

Regarding the properties of drained ice, we note that ice forming under similar conditions during an earlier experiment, and sieved in a similar manner, had similar drained ice salinities, $14<S_{\mathrm{g}}^{\prime}<26$, (and thus likely comparable $\phi_{\mathrm{s}}^{\prime}$ ) to ours (Wilkinson, 2005). However, a discrepancy between our observations and other previous work appears in Figure 5c for the solid volume fraction, $\phi_{\mathrm{s}}^{\prime}$, of drained frazil crystals. Our values are typically $30 \%$ lower than those derived from the laboratory experiments of Martin and Kauffman (1981) and Reimnitz and others (1993). Interestingly in both studies, while the bulk solid fraction of grease, $\phi_{\mathrm{s}}$, was comparable with ours, the solid fraction of frazil crystals, $\phi_{\mathrm{s}}^{\prime}$, was larger, meaning that more brine could be removed than from our samples. Two differences with respect to these experiments are noteworthy. The first is the rate of grease formation; the second is the method of draining. In the experiments of Martin and Kauffman (1981) a grease layer of comparable thickness formed typically within 1 hour, i.e. $>10$ times faster than in our tank experiment, indicating much larger surface heat fluxes. In the experiments of Reimnitz and others (1993), crystals were grown by cooling at the bottom of magnetically stirred 1.8$1.9 \mathrm{~m}$ high tubular tanks. To form an equivalent thickness of $\sim 0.5 \mathrm{~cm}$, sufficient for first sampling of young ice, took 20-40 min, which, compared with our experiments, also indicates an order-of-magnitude faster growth. Martin and Kauffman (1981) drained their samples in funnels, Reimnitz and others (1993) blew air through the grease samples, while we sieved our samples to remove the brine. One might thus, on the one hand, interpret the different $\phi_{\mathrm{s}}^{\prime}$ in terms of the different procedures to remove the brine. On the other hand, the more rapid growth is likely to result in a different crystal structure. These aspects are further discussed below.

Recalling from the equations section that the sea-water approximation for the brine salinity implies an uncertainty of $\mathrm{d} \phi_{\mathrm{s}} / \mathrm{d} S_{\mathrm{b}} \approx-\left(M_{\mathrm{g}}^{\prime} / V_{\mathrm{g}} \rho_{\mathrm{i}}\right)\left(S_{\mathrm{g}}^{\prime} / S_{\mathrm{b}}^{2}\right)$, we use the observations of $S_{\mathrm{g}}^{\prime}$ in Figure $5 \mathrm{a}$, and $S_{\mathrm{b}} \approx S_{\mathrm{w}} \approx 34$ for the tank water, to obtain corrections of the solid fraction in cases of a higher brine salinity (note that for our observations $M_{\mathrm{g}}^{\prime} / V_{v} g \rho_{\mathrm{i}} \approx 0.5-0.6$ ). Unfortunately, we did not measure $S_{\mathrm{b}}$. However, thermistor data from a vertical position that, due to waves, fluctuated between water and grease did not show temperature fluctuations more than $0.1 \mathrm{~K}$ (which was, however, the limited precision of the sensors). We thus assume, in accord with other studies discussed above, that the brine salinity did not exceed the water value by more than $1-2$. For mode I $\left(S_{\mathrm{g}}^{\prime} \approx 24\right), \phi_{\mathrm{s}}$ might then be too small by $0.01-0.02$, while for mode II $\left(S_{\mathrm{g}}^{\prime} \approx 17\right)$ the typical underestimate would be $0.007-0.015$. These numbers need in turn to be corrected due to the volume fraction of air. Assuming $\phi_{\mathrm{a}} \approx 0.01$ we obtain, from Eqn (24), a typical reduction of 0.009 and 0.007 for modes I and II, respectively. Hence, errors due to simplifications made in our analysis appear to cancel partially and our solid fractions are likely underestimated by not more than 0.01 . We now first make a simple approach to model the overall evolution of our observations of the solid fraction (Fig. $5 d$ ) with thickness, before we discuss the noted discrepancies with other observations.

\section{Solid-fraction evolution}

Little is known about the temporal and vertical evolution of the solid fraction of grease ice that, to our knowledge, has not been investigated in earlier work. As shown above, Figures 5 and 6 indicate a slow transition between the initial low solid fraction near 0.1 and the maximum values approximately three times as large. Such compaction was also noted by Reimnitz and others (1993) during the accumulation of a $30 \mathrm{~cm}$ thick grease layer, yet no quantitative analysis has been obtained to date. In the following we propose a simple approach to model the compaction of grease under its own buoyancy, assuming that (1) there is a maximum $\phi_{\text {smax }}$ to which the solid fraction can be compacted, (2) the compaction is proportional to the degree of compaction or difference between the actual local solid fraction, $\widetilde{\phi}_{\mathrm{s}}$, and its maximum and (3) the compaction proceeds vertically, with increasing cumulative equivalent thickness distance, $z_{\mathrm{e}}$, from the ice/water interface. The latter is defined as $z_{\mathrm{e}}=\int_{0}^{z} \widetilde{\phi}_{\mathrm{s}} \mathrm{d} z$, 


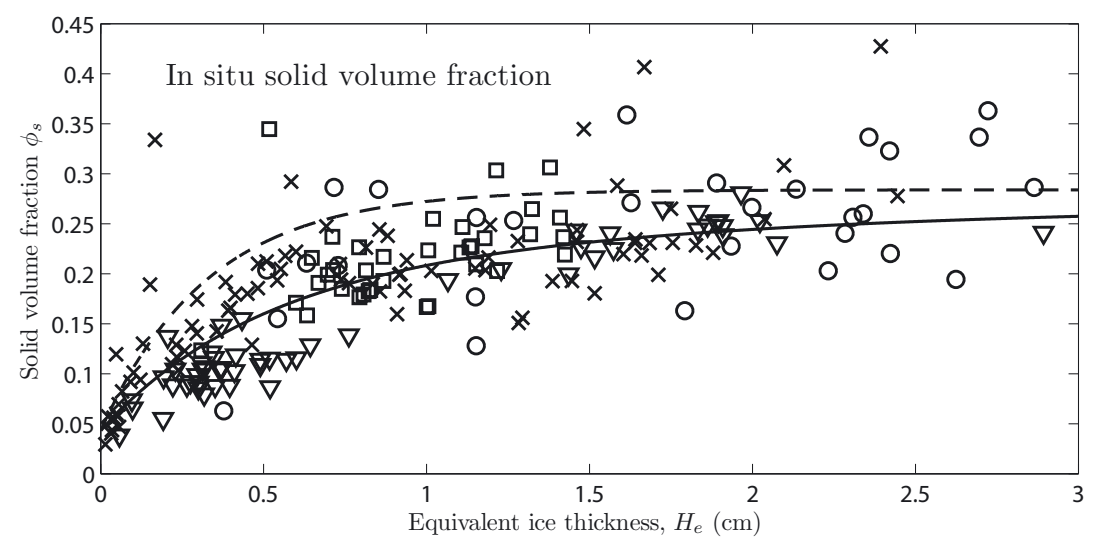

Fig. 7. Grease ice solid volume fraction, $\phi_{\mathrm{S}}$, versus equivalent ice thickness $H_{\mathrm{e}}$. The solid curve is the fit of Eqn (29) to the observations, also shown in Figure 5d, with different symbols denoting four different experiments. The dashed curve is Eqn (28), and gives the predicted solid volume fractions at the surface. The curves correspond to the regression excluding data with $\phi_{\mathrm{s}}>0.30$, leading to $\phi_{\mathrm{smax}}=0.284$ and $\phi_{\mathrm{s} 0}=0.043$.

where the grease/water interface is at $z=0$, and the physical distance, $z$, is measured positively upward. A level $z_{\mathrm{e}}$ thus reflects the thickness of solid ice that, in turn, produces a proportional upward buoyancy force. Assumptions (1-3) may be cast into the equation

$$
\frac{\mathrm{d}}{\mathrm{d} z_{\mathrm{e}}}\left(\phi_{\mathrm{smax}}-\widetilde{\phi}_{\mathrm{s}}\left(z_{\mathrm{e}}\right)\right)=-c\left(\phi_{\mathrm{smax}}-\widetilde{\phi}_{\mathrm{s}}\left(z_{\mathrm{e}}\right)\right),
$$

and hence an exponential decay law with the solution

$$
\widetilde{\phi}_{\mathrm{s}}\left(z_{\mathrm{e}}\right)=\phi_{\mathrm{smax}}-\left(\phi_{\mathrm{smax}}-\phi_{\mathrm{s} 0}\right) \mathrm{e}^{-c z_{\mathrm{e}}},
$$

with $\phi_{\mathrm{s} 0}=\widetilde{\phi}_{\mathrm{s}}\left(z_{\mathrm{e}}=0\right)$. Note that $c^{-1}$ then represents an exponential decay equivalent distance or thickness. So far we have been dealing with and observing average solid fractions, $\phi_{\mathrm{s}}$, of grease of thickness $H_{\mathrm{e}}$, rather than local $\widetilde{\phi}_{\mathrm{s}}$. To obtain this average $\phi_{\mathrm{s}}=H_{\mathrm{e}}^{-1} \int_{0}^{H_{\mathrm{e}}} \widetilde{\phi}_{\mathrm{s}} \mathrm{d} z_{\mathrm{e}}$, we integrate Eqn (28) from the grease/water interface $\left(z_{\mathrm{e}}=0\right)$ to the grease surface $\left(z=H_{\mathrm{e}}\right)$ and obtain

$$
\phi_{\mathrm{s}}\left(H_{\mathrm{e}}\right)=\phi_{\mathrm{smax}}+\frac{\phi_{\mathrm{smax}}-\phi_{\mathrm{s} 0}}{c H_{\mathrm{e}}}\left(1-\mathrm{e}^{-c H_{\mathrm{e}}}\right) .
$$

We henceforth use $\phi_{\mathrm{s}}$ when discussing the average from this equation, and $\widetilde{\phi}_{\mathrm{s}}$ when using local values from Eqn (28). Note that Eqn (29) gives the average solid ice volume fraction of grease ice of equivalent thickness $H_{\mathrm{e}}$, while Eqn (28) gives the profile of the solid volume fraction, and by inserting $H_{\mathrm{e}}$ one obtains the maximum value at the surface. For large $H_{\mathrm{e}}$ both $\widetilde{\phi}_{\mathrm{s}}\left(H_{\mathrm{e}}\right)$ and $\phi_{\mathrm{s}}\left(H_{\mathrm{e}}\right)$ approach $\phi_{\mathrm{smax}}$.

Next, Eqn (29) was fitted to the average solid-fraction data in Figure $5 \mathrm{~d}$ for different $\phi_{\mathrm{smax}}$ to obtain $\phi_{\mathrm{s} 0}$ and $c$ by nonlinear regression, and from the solutions the $\phi_{\text {smax }}$ that minimizes the residuals was determined. This was performed using the functions 'nlinfit.m' and 'nlparci. $m$ ' in MathWorks (2010). We did this for all data and for a subset that excludes observations above $\phi_{\mathrm{s}}=0.30$. On the one hand, this cutoff is motivated by the fact that most other studies have few observations of grease with $\phi_{\mathrm{s}}>0.30$. On the other hand, we argue that the distributions in Figure $6 \mathrm{a}$, in particular at lower thicknesses, indicate that values of $\phi_{\mathrm{s}}>0.30$ are exceptional, and do not resemble the average compaction. Almost all excluded values also appear as anomalous in terms of the grease salinity trend in Figure 5b, where they fall below $S_{\mathrm{g}} \approx 25$. This indicates that this grease is already in an enhanced stage of freezing and desalination.

The best fit for the subset $\phi_{\mathrm{s}}<0.30$ then gives $\phi_{\mathrm{smax}}=$ 0.284 , with a sample minus model standard deviation of 0.019 , a decay thickness of $c^{-1}=0.33 \mathrm{~cm}$ (with $95 \%$ significance bounds $0.287-0.388)$ and $\phi_{\mathrm{s} 0}=0.043(95 \%$ bounds \pm 0.017$)$. When all data are included, the results are only slightly different. The residuals are then minimized for $\phi_{\text {smax }}=0.307$ with a sample minus model standard deviation of 0.025 . The decay thickness scale is slightly larger, $c^{-1}=0.40 \mathrm{~cm}$ (bounds $0.345-0.485$ ), and the initial solid fraction $\phi_{\mathrm{s} 0}=0.053$ (bounds \pm 0.020 ) also. The curves shown in Figure 7 are based on the best-fit parameters for data with $\phi_{\mathrm{s}}>0.30$ excluded. They represent the average solid fraction and the maximum solid fraction at the grease surface, respectively. Recall that the observations are average values and fitted by the solid lower curve. For the dashed curve, the maximum solid fraction at the grease surface, we do not have observations with which to compare. This curve approaches the asymptotic value, $\phi_{\text {smax }}=0.284$, after accumulation of $\sim 1 \mathrm{~cm}$ of solid ice. This is related to the decay scale of $c^{-1}=0.33 \mathrm{~cm}$, implying that at an equivalent thickness distance, $z_{\mathrm{e}}$, of $3 c^{-1} \approx 0.99 \mathrm{~cm}$ about $1-\mathrm{e}^{-3} \approx 95 \%$ of the maximum compaction has been achieved. The maximum of $\phi_{\mathrm{smax}}=0.307$, and $3 c-1=$ $1.2 \mathrm{~cm}$, obtained when all data points are included, is similar. Hence, the packing model approach results in a threshold solid fraction that is consistent with the upper bound from grease ice observations discussed above. The initial solid fraction, $\phi_{\mathrm{s} 0}=0.043$, obtained for $\phi_{\mathrm{s}}<0.30$ (and 0.053 for all data) appears a little lower than the lowest values from field observations.

The only study we can compare with the decay thickness scale and the limiting $\phi_{\text {smax }}$ is Martin and Kauffman (1981). From our Figure 1 the average $\phi_{\mathrm{s}}$ in these experiments appears to saturate at $0.18-0.22$ (in the 'dead zone'). The corresponding grease ice thickness (table II of Martin and Kauffman, 1981) is $7-12 \mathrm{~cm}$. Using $9 \mathrm{~cm}$ (as the average for the runs) gives a corresponding equivalent ice thickness of $1.6-2.0 \mathrm{~cm}$, which appears larger than our $95 \%$ compaction decay thickness scale of $3 c^{-1} \approx 1.0-1.2 \mathrm{~cm}$. However, recalling Figure 7 , the decay scale relates to the solid-fraction limit at the surface, while the average solid fraction is still 
increasing near $3 c^{-1}$. Considering this, and the horizontal gradient in both thickness and solid fraction in Figure 1, the corresponding critical thickness scale would be closer to ours in Figure 7. Also, when evaluating the range $1.6-2.0 \mathrm{~cm}$ with Eqn (29) and our fitted parameters, one obtains $\phi_{\mathrm{s}} \approx 0.24$, about 0.04 larger than observed by Martin and Kauffman (1981). We note further that we had corrected the solid ice volume fraction with the constant drained ice salinity of $S_{\mathrm{g}}^{\prime}=11.8$ given by Martin and Kauffman (1981), who did not provide the ice salinity evolution with thickness. If we assume a similar relative trend for their drained grease salinity, $S_{\mathrm{g}}^{\prime}$, to that in Figure 5, with 20\% higher (lower) values towards low (large) thickness, the corrected highend $\phi_{\mathrm{s}}$ would increase by 0.02 , while the lowest values would decrease by 0.01 , improving the agreement with our parametric fit.

Due to an approximately constant heat loss in the experiments (De la Rosa and Maus, 2011), an equivalent thickness of $1 \mathrm{~cm}$ corresponds typically to 12 hours of ice growth (see also Fig. 6 and its discussion). The derived $95 \%$ compaction decay scale of $1.0 \mathrm{~cm}$ could thus also be interpreted in terms of a timescale of 12 hours. From our constant heat flux runs we cannot determine whether time or thickness controls the decay. However, in the experiments of Martin and Kauffman (1981) a similar equivalent $1 \mathrm{~cm}$ of solid ice was grown in $<1$ hour. This suggests that the equivalent thickness rather than the time controls the degree of compaction.

\section{Vertical profile estimation}

The fits may also be represented in a different way. As the proposed model only considers the dependence of the solid fraction on the cumulative ice mass or equivalent thickness, Eqn (28) reflects a unique vertical solid-fraction profile, where the coordinate $z_{\mathrm{e}}$ is measured upward from the lower grease boundary. This solid-fraction/thickness profile, obtained by transforming equivalent to physical thickness by inversion of $z_{\mathrm{e}}=\int_{0}^{z} \widetilde{\phi}_{\mathrm{s}} \mathrm{d} z$, is illustrated in Figure 8, up to a thickness of $10 \mathrm{~cm}$. For thinner grease, all profiles start at the lowest bottom value $($ at $-10 \mathrm{~cm})$ and end at some higher surface value corresponding to the grease thickness. Hence, the $95 \%$ compaction limit is indicated by ' $(\mathrm{L})$ ' and the upper horizontal line in the figure, while a lower horizontal line indicated by ' $(\mathrm{I})^{\prime}$ ' is drawn slightly above the grease/water interface (water shown in grey). Note that this line is $\sim 0.5 \mathrm{~cm}$ above the lowest concentration, $\phi_{\mathrm{s} 0}=0.043$, at the end of the profile. To obtain this level, we considered that the grease samples were taken with a $60 \mathrm{~cm}$ long cylinder, submerged $30-40 \mathrm{~cm}$ into the water column (Fig. 4), and thus may be biased by fresh frazil that rapidly rises during sampling (1-2 min). Assuming a suspended frazil volume fraction of 0.001 , a realistic value discussed by De la Rosa and Maus (2011) and observed by Smedsrud (2001) for similar tank experiments, implies a potential equivalent ice thickness of $30-40 \times 0.001 \approx 0.03-0.04 \mathrm{~cm}$ from the water column. Interpreting this as a bias, $0.03-0.04 \mathrm{~cm}$ can be inserted in Eqn (28), which then gives the corrected and lower bound of $\phi_{\mathrm{s} 0} \approx 0.06-0.07$. This level should be interpreted as the true grease/water interface or lower boundary of the grease layer, and thus the lowest possible packing reflected by the model fit. The 95\% maximum compaction limit thus appears $\sim 4 \mathrm{~cm}$ from this 'new' grease/water interface, implying that grease

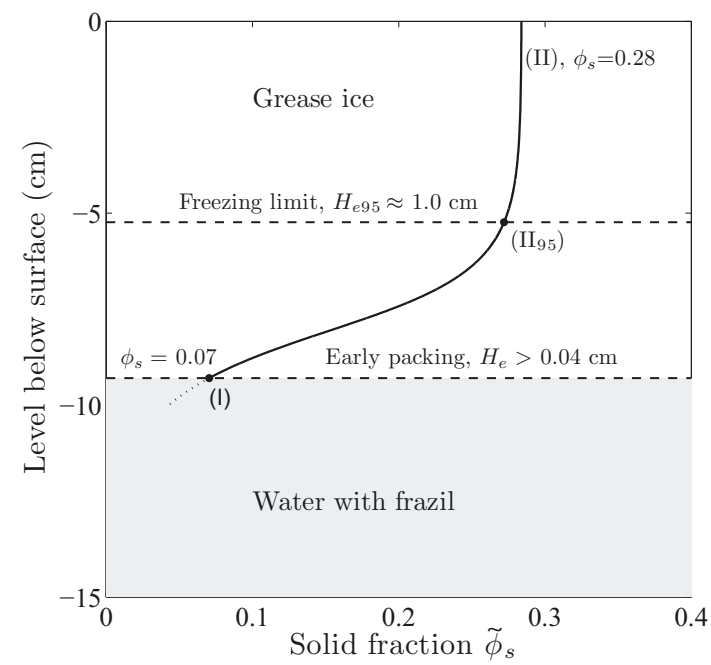

Fig. 8. Solid-volume-fraction profile of $10 \mathrm{~cm}$ grease based on the model fit of Eqn (28). The horizontal lines indicate (I) the initial solid fraction at the grease ice/water interface, when corrected for the frazil crystals sampled from a $30-40 \mathrm{~cm}$ water column (these presumably created the lowermost $0.5 \mathrm{~cm}$ of the solid-fraction profile), and ( $\mathrm{I}_{95}$ ) the level where $95 \%$ of the maximum packing before freezing is attained and $\phi_{\text {smax }}$ has almost been reached (three times the decay thickness scale, $\sim 1 \mathrm{~cm}$ ). Note that the model implies that $\widetilde{\phi_{S}}$ is only a function of the distance from the grease/water interface, i.e. $5 \mathrm{~cm}$ thick grease would correspond to the lower $5 \mathrm{~cm}$ of the profile.

has to accumulate to this thickness for its upper boundary to become close to compacted.

In principle, one should correct the observations for the bias due to crystals from the water column before the fitting procedure. However, the data at low $H_{\mathrm{e}}$ are sparse and we do not have sufficient information on the water column and the crystal rise during sampling. The amount of frazil in suspension will also depend on the wave action (e.g. in the experiments the amplitude varied between 1 and $6 \mathrm{~cm}$ (De la Rosa and Maus, 2011)). We note that, carrying out the regression after plausible corrections as described, one obtains higher $\phi_{\mathrm{s} 0} \approx 0.05-0.10$, while $\phi_{\text {smax }}$ increases by 0.01 (not shown). The discussed apparent early solidvolume-fraction mode (I) of $0.08<\phi_{\mathrm{s}}<0.12$ in Figure 6 also increases slightly, by 0.01 . Also, the tentative initial value of $\phi_{\mathrm{s} 0} \approx 0.07$ at the lower grease boundary is a zerothickness limit, while for packing a certain volume of crystals is necessary. To account for this, one should insert a thickness larger than the water column bias of $0.04 \mathrm{~cm}$ into Eqn (28). Moving upward from the grease/water interface in Figure 8 by $1 \mathrm{~cm}$, this yields an average $\phi_{\mathrm{s}} \approx 0.10$, close to the early packing limit. Such a physical thickness of at least a few times the typical frazil crystal or floc diameter of $\sim 1-3 \mathrm{~mm}$ (Gosink and Osterkamp, 1983; Clark and Doering, 2006) may be a plausible limit for random packing to be defined. Clearly, for further discussion, observations of profiles of solid fraction in grease are needed. The main point of the present considerations is thus that a tentative correction for frazil from the water column (due to our sampling procedure) increases the model estimate of the initial solid fraction to $\phi_{\mathrm{s} 0} \approx 0.07$, while the need for a finite layer thickness may imply a higher value of $\sim 0.10$ when interpreting the model fit. This inferred range is in agreement with other observations 
of very young grease, in particular the laboratory data of Martin and Kauffman (1981) and Reimnitz and others (1993) discussed above.

\section{Compaction versus freezing}

While we have fitted the data by a simple compaction approach, this can only approximate the evolution of the grease cover. It is an attempt to describe the continuous accumulation of new frazil rising from the water column, assuming that it occurs in a kind of steady state. In terms of earlier modelling, this corresponds to the stage when single frazil crystals, by sticking to each other and forming larger flocs, acquire a large terminal rise velocity and float to the surface (e.g. Gosink and Osterkamp, 1983; Andreasson and others, 1998; Morse and Richard, 2009). As long as heat is removed from the turbulent upper layer below the grease, new crystals can nucleate, while others will break up and are eventually transported back downward into the fluid, and continue their growth and interaction. The fluid can only keep a certain amount of frazil in suspension and the supply of frazil to the grease layer continues from below. As noted in earlier studies, such a quasi-steady state may be realistic, but will depend on many conditions, such as the initial supercooling and nucleation of crystals, their secondary nucleation and flocculation, heat fluxes and the details of the turbulent mixing (e.g. Omstedt and Svensson, 1984; Svensson and Omstedt, 1994; Wang and Doering, 2005; Clark and Doering, 2009). Furthermore, the grease ice will change its solid fraction thermodynamically due to internal freezing. The proposed compaction equation is tentative and does not distinguish mechanical packing and thermodynamic solid-fraction increase. However, the data provide some ideas on this question.

In the histogram (Fig. 6a) of the solid fraction, two modes were apparent, an initial one with $0.08<\phi_{\mathrm{s}}<0.12$, and a broader one with $0.18<\phi_{\mathrm{s}}<0.26$. While the former may be associated with a rapid mechanical packing state, the broader mode appears consistent with an increase in the solid fraction due to internal freezing. Its fitted upper limit, $0.28<\phi_{\text {smax }}<0.31$, may then be interpreted as the solid fraction at which the grease ice begins to freeze-up into shuga and pancakes. This conjecture is consistent with maximum solid fractions from most other previous studies, as well as a recent thermodynamic analysis of the conditions during the grease-to-pancake transition at a later stage of this experiment (De la Rosa and others, 2011). Regarding the, presumably, mechanical compaction mode, one might argue that, when the average $\phi_{\mathrm{s}}\left(H_{\mathrm{e}}\right) \approx 0.10$ is reached (at $H_{\mathrm{e}} \approx 0.19 \mathrm{~cm}$ ), Eqns (28) and (29) imply a corresponding surface solid volume fraction of $\widetilde{\phi}_{\mathrm{s}} \approx 0.15$ (Fig. 7). This might thus be more strictly interpreted as the compaction limit. However, due to the lack of profile observations, the available average solid-fraction data are insufficient to fully validate the compaction model. Hence, we conjecture that a mechanical packing limit is reached in the range $0.10<$ $\widetilde{\phi}_{\mathrm{s}}<0.15$.

Mechanical compaction of particles is known to depend on shape. Of particular interest for particles with ideal shapes are the ratios of their principal-axis lengths, like the sides of a rectangle or an ellipse. Simple three-dimensional (3-D) objects may also be characterized by a single 'aspect

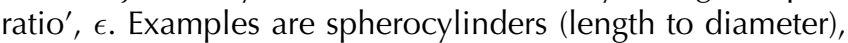
fibres (length to thickness) and discs (diameter to thickness).
While the random close packing limit for spheres is typically $\phi_{\text {sp }} \approx 0.64$ (Berryman, 1983; Torquato and others, 2000), the latter decreases with the aspect ratio, $\epsilon$. In the large-aspectratio limit of $\epsilon>15$ the approximation

$$
\phi_{\mathrm{sp}} \approx \frac{B}{\epsilon}
$$

often describes the data. $B$ depends on shape but is similar for pennies, cylinders and oblate and prolate spheroids, being typically in the range 5-5.5 (e.g. Rahli and others, 1999; Williams and Philipse, 2003; Blouwolff and Fraden, 2006; Wouterse and others, 2007). Rahli and others (1999) have suggested a modified formula for the packing of rigid fibres,

$$
\phi_{\mathrm{sp}} \approx \frac{11}{\frac{\pi}{2 \epsilon}+6+2 \epsilon},
$$

which also describes observations at moderate aspect ratios down to $\epsilon \approx 10$. We apply this formula henceforth to the packing of frazil discs or crystals, which have been described as having the form of long needles or flat discs (Arakawa, 1954; Bukina, 1963; Martin, 1981; Daly, 1991; Clark and Doering, 2006).

In Figure 9 we plot Eqn (31) as a solid line for the regime relevant for frazil crystals. The equation is shown until it predicts $\phi_{\mathrm{sp}}>0.64$, the sphere-packing limit, which happens near $\epsilon=5.5$. In the range $5.5<\epsilon<10$ the equation is known to overestimate the solid fraction, as the transition to sphere packing takes place in a smooth manner. However, this has little impact on the following discussion of values near or above $\epsilon=10$. To compare this curve with the main results from the present analysis, we plot these as two tentative horizontal lines, $\phi_{\mathrm{s}}=0.12$ representing the first solid-fraction mode (in the middle of the suggested range), and $\phi_{\text {smax }}=0.28$ for the ultimate packing/freezing limit. The diamonds show where these lines cut the predicted solid fraction of random close packing, $\phi_{\mathrm{sp}}$. Numerically, the aspect ratio is obtained by inserting $\phi_{\mathrm{S}}$ on the left-hand side of Eqn (31). Using $0.12<\phi_{\mathrm{s}}<0.28$ spans the range $17<\epsilon<43$. Looking at the grey shading at the bottom of the figure, this regime agrees reasonably with aspect ratios that have been proposed on the basis of rise velocities (Gosink and Osterkamp, 1983).

However, this match assumed that crystals are pure and non-porous, which is known not to be the case for frazil ice grown from saline solutions, where crystals tend to be rather dendritic or agglomerate into flocs (Martin, 1981; Hanley and Tsang, 1984; Tsang and Hanley, 1985; Smedsrud, 2001). This is also the likely cause for the large amount of brine that remained in the ice samples after sieving. To proceed, we make use of the characteristics of sieved ice, and recall the results for the solid volume fraction, $\phi_{\mathrm{s}}^{\prime}$, of the crystals, shown in Figure $5 \mathrm{c}$. At the beginning of the experiment $\phi_{\mathrm{s}}^{\prime} \approx 0.3$ and it reached a value of $\sim 0.55$ towards the end, corresponding to brine porosities of $\phi_{\mathrm{b}}^{\prime}=0.7$ and 0.45 , respectively. We thus rescale the right-hand side of Eqn (31), multiplying by $\phi_{\mathrm{s}}^{\prime}$, to obtain the two downward-shifted predictions of $\phi_{\mathrm{sp}}$ for porous particles. These are shown as dashed and dasheddotted lines. Next, combining the early packing limit of $\phi_{\mathrm{s}} \approx 0.12$ with the initial sieved ice solid fraction $\phi_{\mathrm{s}}^{\prime} \approx 0.3$ and the late maximum packing fraction of $\phi_{\mathrm{S}} \approx 0.28$ with the late sieved-ice solid fraction $\phi_{\mathrm{s}}^{\prime} \approx 0.55$, one obtains the two stars on the left-hand side, labelled 'porous discs'. The numerical procedure simply consists of replacing $\phi_{\mathrm{s}}$ on the left-hand side of Eqn (31) with $\phi_{\mathrm{s}} / \phi_{\mathrm{s}}^{\prime}$. 


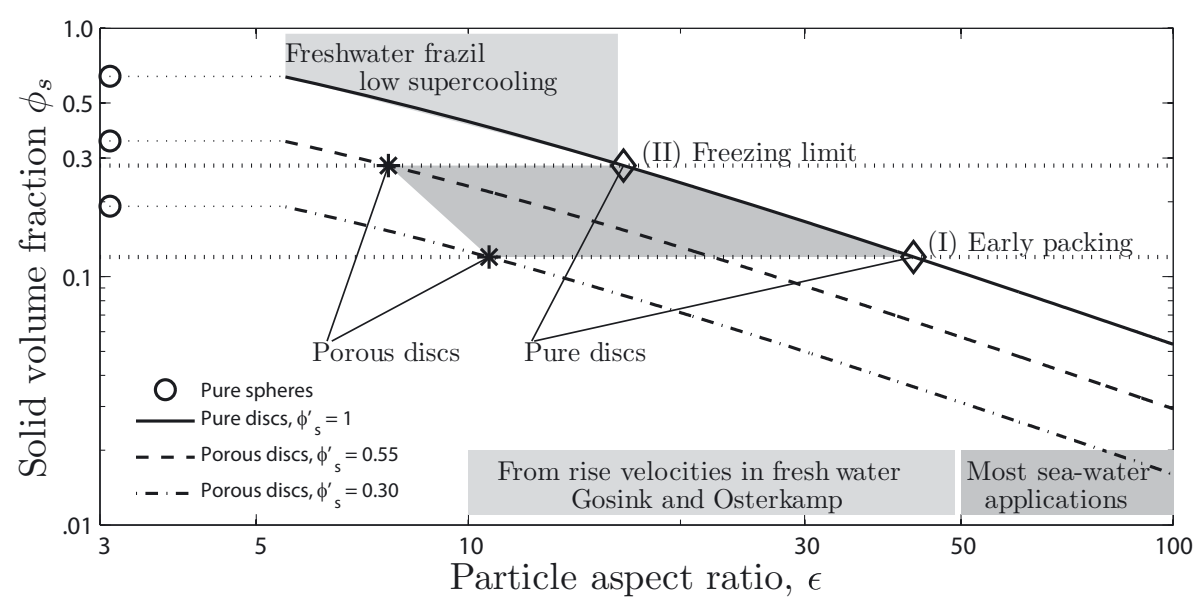

Fig. 9. Maximum random close packing, $\phi_{\mathrm{sp}}$, predicted by Eqn (31), vs crystal aspect ratios, along with the main results from the present analysis of the evolution of the grease ice solid fraction, $\phi_{\mathrm{S}}$, and crystal solid fraction, $\phi_{\mathrm{S}}^{\prime}$. The upper curve is for crystals or flocs with zero porosity $\left(\phi_{\mathrm{S}}^{\prime}=1\right)$, the other two curves for lower solid fractions $\phi_{\mathrm{S}}^{\prime}=0.3$ and 0.55 , as determined for the early (I) and late (II) stages of grease. For these stages the respective typical bulk solid-fraction modes proposed are (I) $\phi_{\mathrm{S}}=0.12$ and (II) $\phi_{\mathrm{S}}=0.28$, shown as dotted horizontal lines. The stars indicate where the observations match the random packing, and indicate crystal aspect ratios around 10. Such values are in agreement with freshwater frazil observations (upper grey shading), but not with model approaches (lower shadings).

The use of all information, i.e. the solid fraction of drained and undrained grease, then indicates that an aspect ratio of $8<\epsilon<11$ is most consistent with the data. Note also that the decrease in sieved frazil brine porosity, $\phi_{\mathrm{b}}^{\prime}$, is consistent with the interpretation that mode II is created by internal freezing. The internal freezing of flocs, prior to freezing of brine between the flocs, in turn would keep the critical aspect ratio constant. This is indeed indicated by the present analysis (by assuming a slightly higher $\phi_{\mathrm{s}} \approx 0.15$ for the early packing, one would obtain the same $\epsilon \approx 8$ as for mode II). It should be noted that the liquid fraction of sieved frazil, $\phi_{\mathrm{b}}^{\prime}$, probably overestimates the true porosity of the flocs, due to brine also adhering to the outer surface of flocs and tiny crystals. Another issue is the possibility of crystal orientation in grease, which would allow for denser packing than the random scaling. At present there are no observations that clearly demonstrate whether crystals, or platelets, orientate during the compaction process of frazil ice, once the water and wave motion becomes weak. Martin and Kauffman (1981) noted that they found crystals oriented with their $c$-axes horizontal, and their main growth plane vertical, while Wilkinson (2005) reports observing the opposite in pancakes that formed from frazil in tank experiments. As the results from Martin and Kauffman (1981) are from a $2 \mathrm{~m}$ laboratory tank, confinement may have influenced the way in which the turbulence is damped and eventually compressed the crystals horizontally. Field observations of solidified platelet ice from the bottom of an Antarctic ice shelf (Tison and others, 1993) show both random orientation and crystals with primarily horizontal $c$-axes (disc planes vertical) and, in addition, strong alignment of the $c$-axes. The authors interpreted the alignment in terms of ocean currents, which compares with observations for columnar sea ice (Weeks and Gow, 1978), where it is related to the vertical growth process rather than crystal rise dynamics. As noted by Dempsey and others (2010), the orientation of crystals in solid ice may not reflect their orientation during accumulation. The latter authors' simulations did not include waves or currents, which are likely to play an important role for frazil forming near the surface. Hence, observations are necessary of both the orientation of frazil crystal assemblages in freshly accumulated grease and the internal microstructure of single crystals or flocs.

The influence of the shape of frazil crystals on the early packing and freezing transition is, mostly indirectly, relevant in many applications (e.g. orientation of frazil crystal assemblages, modelling of supercooling and frazil growth (e.g. Omstedt and Svensson, 1984; Svensson and Omstedt, 1994; Wang and Doering, 2005), wave/grease interactions (De Carolis and others, 2005; Wang and Shen, 2010), frazil dynamics along the bottom of ice shelves (Jenkins and Bombosch, 1995; Holland and Feltham, 2005) and interaction of platelet dynamics and salt fluxes (McGuiness and others, 2009)). In most of these applications aspect ratios in the range 50-100 have been used, much larger than our present study indicates.

How variable might the critical solid fraction modes be? Considering crystal shapes and aspect ratios, most observations to date are for freshwater frazil crystals and fall in the range 5-15 (Bukina, 1963; Daly, 1991; Clark and Doering, 2006), with a tendency for larger aspects to form at higher supercooling (Bukina, 1963; Ettema and others, 1984). This crystal shape variability relates to anisotropic growth of single crystals which, in turn, is a complex function of boundary conditions (i.e. turbulence and supercooling) dissolved salts and their concentration (e.g. Michaels and others, 1966; Yokoyama and others, 2000). The relevance of molecular details is suggested by observations that saline and freshwater frazil crystals grow and behave differently (Hanley and Tsang, 1984; Tsang and Hanley, 1985). In this context, a change in aspect ratio due to surface-energydriven Ostwald ripening (e.g. Pronk and others, 2005) might also play a significant role for the early evolution of grease. Random packing depends on shape, with discs packing slightly denser than spherocylinders of the same aspect (e.g. Wouterse and others, 2007). Also, the loosest way to pack spheres, random loose packing, is $\sim 14 \%$ less dense than the random close packing that we applied here (e.g. Song and others, 2008). Such details may slightly modify the present results. In general, one may say that high 
supercoolings should create higher aspect ratios and hence lower solid fractions; this might explain, for example, the low solid fraction in laboratory experiments with very high supercoolings (Tyshko and Cherepanov, 1998). However, the fact that supercoolings under natural conditions appear to be limited to values below $0.1 \mathrm{~K}$ (e.g. Altberg, 1936; Carstens, 1966; Martin, 1981; Ashton, 1986; Holland and Feltham, 2005) may explain the moderate range in natural solid volume fractions reported herein.

In terms of different growth conditions, we finally note that the only other work that may indicate the evolution of maximum grease ice solid fraction with time and thickness is Martin and Kauffman (1981). As discussed above, grease bulk solid fractions in their tank indicate a maximum packing limit 0.04 lower than in our data, i.e. $\phi_{\text {smax }} \approx 0.24$. We recall Figure $5 \mathrm{c}$, showing the higher solid fraction of $\phi_{\mathrm{s}}^{\prime} \approx 0.72$ of their drained frazil crystals. Inserting this $\phi_{\mathrm{smax}} / \phi_{\mathrm{s}}^{\prime} \approx 0.33$ on the left-hand side of Eqn (31) then predicts an aspect ratio of $\epsilon \approx 14$, which is larger than the estimate from the present study. On the one hand, considering the higher heat loss rates and ice growth rate in the experiments of Martin and Kauffman (1981), this is qualitatively consistent with the fact that crystal aspect ratios normally increase with heat flux and supercooling (Bukina, 1963; Ettema and others, 1984). On the other hand, the higher $\phi_{\mathrm{s}}^{\prime} \approx 0.72$ compared to our observations (Fig. 5c) might be the consequence of a different drainage protocol. Hence, the simple comparison indicates that crystal growth and shapes may influence the macroscopic packing and properties of grease ice, and also highlights the need for future sensitivity experiments.

\section{CONCLUSIONS}

We have reviewed equations and observations to derive the bulk salinity and solid fraction of grease ice. In particular, we have revised the procedures and equations applied in several previous studies, to obtain the solid fraction of grease ice from observations of the salinity and mass of drained frazil crystals (e.g. Martin and Kauffman, 1981; Smedsrud and Skogseth, 2006). Analysing observations from a recent tank study (De la Rosa and Maus, 2011) we demonstrated here that, for our specific sampling and drainage protocol, there is no stable relation between the sieved (12-30) and bulk (20-33) salinity of grease ice. In previous studies many different sampling and drainage protocols of grease ice have been used, including shipborne sampling with nets (Wadhams and Wilkinson, 1999), drainage in funnels (Martin and Kauffman, 1981), air-blowing through the grease samples (Reimnitz and others, 1993) and sieving the samples for (presumably) different time durations and under different conditions (Wilkinson, 2005; Smedsrud and Skogseth, 2006; De la Rosa and Maus, 2011). The values for drained grease ice salinities reported in the existing literature range between 5 and 28. We thus conclude that a comparison of many earlier studies in terms of the salinity of drained grease is problematic. Moreover, the bulk salinity of grease ice is the relevant parameter when describing thermodynamic processes (e.g. ice/ocean salt fluxes). As salinity ultimately relates to the solid volume fraction, it also affects dynamical and mechanical processes. The salinity of drained grease ice is thus of limited value for modelling these processes.

The analysis of the present tank data indicated two modes of the solid fraction of young grease ice accumulating under wave conditions. A first mode in the range $0.08<$ $\phi_{\mathrm{s}}<0.12$ (for which we estimate surface values of $0.10<$ $\left.\phi_{\mathrm{s}}<0.15\right)$ appears to be associated with the early maximum mechanical packing, while an upper limit, $0.28<\phi_{\text {smax }}<$ 0.31 , is suggested to be related to the maximum solid fraction below which grease can exist, without freezing-up into shuga and pancakes. This conjecture appears consistent with a review of previous observations of maximum solid fractions of grease ice $(0.30-0.35)$ and is supported by a recent study of the grease-to-pancake transition (De la Rosa and others, 2011). It is possible that the present values, based on the drainage method, slightly underestimate the true solid fraction. If the brine had a 1-2 larger salinity than the sea water in which the ice floats, modes I and II could be underestimated by as much as 0.02 and 0.015 , whereas a gas volume of 0.01 would, in turn, reduce these values by 0.009 and 0.007 , respectively. While such brine salinity, $S_{\mathrm{b}}$, and gas volume, $\phi_{\mathrm{a}}$, appear plausible from the limited observations discussed, both properties of grease ice require further study.

We further evaluated the data by comparing the derived modes for the grease solid fraction, i.e. the early packing mode, $0.08<\phi_{\mathrm{s}}<0.12$, and the maximum packing before freeze-up, $0.28<\phi_{\text {smax }}<0.31$, with predictions based on the assumption of random close packing, and its dependence on the aspect ratio of particles. By combining the solid fraction of bulk grease ice, $\phi_{\mathrm{s}}$, with observations of the solid fraction of sieved frazil crystals, $\phi_{\mathrm{s}}^{\prime}$, we showed that the observed solid fractions are consistent with porous frazil flocs that have an aspect ratio of $\sim 10$. This value is much smaller than that assumed in many model applications of oceanic frazil ice processes (e.g. Omstedt and Svensson, 1984; Svensson and Omstedt, 1994; Jenkins and Bombosch, 1995; De Carolis and others, 2005; Holland and Feltham, 2005; McGuiness and others, 2009; Wang and Shen, 2010), yet consistent with direct observations of freshwater frazil discs and flocs in the range 5-15 (Bukina, 1963; Daly, 1991; Clark and Doering, 2006).

The conclusions highlight that predictions of frazil and grease processes require models that link molecular aspects of crystal growth to mechanical crystal interaction and fluid turbulence, whereas formulations so far have employed crude parameterizations of all categories (e.g. Omstedt and Svensson, 1984; Svensson and Omstedt, 1994; Wang and Doering, 2005). They also point to the importance of microscale observations of frazil crystals to make progress in understanding the dynamics and thermodynamics of grease ice, on microscopic and geophysical scales. To date, detailed crystal size and shape observations are sparse and restricted to freshwater frazil (Bukina, 1963; Daly, 1991; Clark and Doering, 2006), while oceanic field data on the microstructure of grease and frazil ice are lacking. In this respect it will be important to develop sampling, transport and storage procedures that conserve the grease ice microstructure for microscopic analysis.

With regard to the methods we compared to derive the bulk solid fraction, $\phi_{\mathrm{s}}$, of grease ice, we note that the bulk salinity method (1) based on grease salinity, $S_{g}$, alone is the simplest approach. However, we recommend combining it with observations of drained brine salinity to reduce the uncertainty in $\phi_{\mathrm{s}}$ and to deduce $\phi_{\mathrm{s}}^{\prime}$ of the frazil crystals, of which we have demonstrated a useful application in Figure 9. Also, the method to analyse properties from drained samples, method 4, on which most of our conclusions are based, can 
be improved by collecting the drained brine and measuring its salinity, and thus removing the uncertainty due to the assumption that the sea water equals brine. Besides the lower uncertainty in estimates of $\phi_{\mathrm{s}}$, the drainage method has another practical advantage, being useful when brine loss from grease cannot be avoided (e.g. when large volumes of grease are sampled using a crane from a ship). However, to provide meaningful results of $\phi_{\mathrm{s}}$, the procedure should include observations of the volume of the sample before drainage, which has not been the case in earlier shipborne studies of grease ice (Wadhams and Wilkinson, 1999; Doble and others, 2003).

To validate the ideas proposed in the present study on the vertical distribution and compaction limits of grease, several sampling strategies may be suggested. First, the densitybased method (3) could be used to obtain estimates of the air volume fraction of grease ice, and its influence on the conclusions and calculations. Second, one should sample vertical profiles of grease. A simple practical approach could be to obtain different sample thicknesses from the top boundary by introducing a sampling device stepwise. A special device that samples several vertical sub-layers or slices at the same time would be most useful and should be constructed. Finally, observations of the crystal structure of grease ice are important to validate the dependence of compaction on shape and aspect ratio, as well as growth conditions of crystals. The most feasible approach is probably to drain grease ice and shock-freeze the drained frazil crystals for further microscopic analysis. The shock-frozen brine contained in the crystals or flocs is likely to display a different freezing pattern from the in situ frazil crystals. High-resolution 3-D X-ray tomography (Maus and others, 2009; Pringle and others, 2009) could be an appropriate method to determine microstructural details of grease ice, and relate them to its macroscopic properties, such as solid volume fraction and salinity. In tank studies such grease layer analysis could be further combined with more sophisticated observations of supercooling and suspended frazil in the water column, and systematic sampling of crystals from the latter.

\section{ACKNOWLEDGEMENTS}

We thank Trond Mohn c/o Frank Mohn AS for providing partial funding for this work. Funding was also provided by the NorClim project, funded by the Norwegian Research Council and the RECARO Project supported by the European Community's Sixth Framework Programme through the grant to the budget of the Integrated Infrastructure Initiative HYDRALAB III, contract No. 022441(RII3).

\section{REFERENCES}

Ackermann NL, Shen HT and Sanders B (1994) Experimental studies of sediment enrichment of Arctic ice covers due to wave action and frazil entrainment. J. Geophys. Res., 99(C4), 7761-7770

Altberg WJ (1936) Twenty years of work in the domain of underwater ice formation (1915-1935). IASH Bull., 23, 373-407

Andersson A and Daly SF (1992) Laboratory investigation of trash rack freezeup by frazil ice. CRREL Spec. Rep. 92-16

Andreasson P, Hammar L and Shen HT (1998) The influence of surface turbulence on the formation of ice pans. In Shen HT ed. Ice in Surface Waters: Proceedings of the 14th International
Symposium on Ice, 27-31 July 1998, Potsdam, New York, USA. Balkema, Rotterdam, 69-76

Arakawa K (1954) Studies on the freezing of water. II: formation of disc crystals. J. Fac. Sci., Hokkaido Univ., Ser. 2, 4(5), 311-339

Ashton GD ed. (1986) River and lake ice engineering. Water Resources Publications, Littleton, CO

Barnes HT (1906) Ice formation: with special reference to anchor-ice and frazil. John Wiley, New York

Barnes HT (1928) Ice engineering. Renouf Publishing, Montréal, Que.

Barnes PW, Reimnitz E and Fox D (1982) Ice rafting of fine-grained sediment, a sorting and transport mechanism, Beaufort Sea, Alaska. J. Sediment. Petrol., 52(2), 493-502

Bauer J and Martin S (1983) A model of grease ice in small leads. J. Geophys. Res., 88(C5), 2917-2925

Berryman JG (1983) Random close packing of hard spheres and disks. Phys. Rev. A, 27(2), 1053-1061 (doi: 10.1103/ PhysRevA.27.1053)

Blouwolff J and Fraden S (2006) The coordination number of granular cylinders. Europhys. Lett., 76(6), 1095-1101 (doi: 10.1209/epl/i2006-10376-1)

Bukina LA (1963) On the relation between temperature and ratio of thickness to diameter of frazil ice crystals of disc-like form. Bull. (Izv.) Acad. Sci. USSR, Geophys., 1, 112-114

Carstens T (1966) Experiments with supercooling and ice formation in flowing water. Geofys. Publ., 26(9), 1-18

Cherepanov NV and Kozlovskii AM (1973) Underwater ice in the coastal waters of Antarctica. Sov. Antarct. Exped. Inf. Bull., 8(6), 335-338

Clark S and Doering J (2006) Laboratory experiments on frazilsize characteristics in a counterrotating flume. J. Hydraul. Eng., 132(1), 94-101 (doi: 10.1061/(ASCE)0733-9429(2006)132:1)

Clark SP and Doering JC (2009) Frazil flocculation and secondary nucleation in a counter-rotating flume. Cold Reg. Sci. Technol., 55(2), 221-229 (doi: 10.1016/j.coldregions.2008.04.002)

Coachman LK (1966) Production of supercooled water during sea ice formation. In Fletcher JO ed. Proceedings of the Symposium on the Arctic Heat Budget and Atmospheric Circulation, 31 January-4 February 1966, Lake Arrowhead, CA, USA. Rand Corporation, Los Angeles, 497-529 (Rand Corporation Research Memorandum RM-5233-NSF)

Daly SF (1991) Frazil ice. In Cheng KC and Seki N eds. Freezing and melting heat transfer in engineering: selected topics on icewater systems and welding and casting processes. Hemisphere, New York

De Carolis G, Olla P and Pignagnoli L (2005) Effective viscosity of grease ice in linearized gravity waves. J. Fluid Mech., 535, 369-381 (doi: 10.1017/S002211200500474X)

De la Rosa S and Maus S (2011) Laboratory study of frazil ice accumulation under wave conditions. Cryos. Discuss., 5(4), 1835-1886 (doi: 10.5194/tcd-5-1835-2011)

De la Rosa S, Maus S and Kern S (2011) Thermodynamic investigation of an evolving grease to pancake ice field. Ann. Glaciol., 52(57 Pt 2), 206-214 (doi: 10.3189/172756411795931787)

Dempsey DE, Langhorne PJ, Robinson NJ, Williams MJM, Haskell TG and Frew RD (2010) Observation and modeling of platelet ice fabric in McMurdo Sound, Antarctica. J. Geophys. Res., 115(C1), C01007 (doi: 10.1029/2008JC005264)

Devik O (1944) Ice formation in lakes and rivers. Geogr. J., 103(5), 193-203

Doble MJ (2007) Growth and motion at the Weddell Sea ice edge. (PhD thesis, University of Southampton)

Doble MJ, Coon MD and Wadhams P (2003) Pancake ice formation in the Weddell Sea. J. Geophys. Res., 108(C7), 3029-3030 (doi: 1029/2002JC001373)

Doronin YuP and Kheisin DE (1977) Sea ice. Amerind Publishing Co., New Delhi.

Ettema R, Karim MF and Kennedy JF (1984) Laboratory experiments on frazil growth in supercooled water. Cold Reg. Sci. Technol., 10(1), 43-58 
Ettema R, Kirkil G and Daly S (2009) Frazil ice concerns for channels, pump-lines, penstocks, siphons, and tunnels in mountainous regions. Cold Reg. Sci. Technol., 55(2), 202-211 (doi: 10.1016/j.coldregions.2008.04.008)

Fofonoff NP and Millard RC, Jr (1983) Algorithms for computation of fundamental properties of seawater. UNESCO Tech. Pap. Mar. Sci. 44

Frankenstein G and Garner R (1967) Equations for determining the brine volume of sea ice from -0.5 to $-22.9^{\circ} \mathrm{C}$. J. Glaciol., $\mathbf{6}(48)$, 943-944

Gosink JP and Osterkamp TE (1983) Measurements and analyses of velocity profiles and frazil ice-crystal rise velocities during periods of frazil-ice formation in rivers. Ann. Glaciol., 4, 79-84

Gradinger R and Ikävalko J (1998) Organism incorporation into newly forming Arctic sea ice in the Greenland Sea. J. Plankton Res., 20(5), 871-886

Gross GW, Wong PM and Humes K (1977) Concentration dependent solute redistribution at the ice-water phase boundary. III. Spontaneous convection. Chloride solutions. J. Chem. Phys., 67(11), 5264-5274

Hanley TO and Tsang G (1984) Formation and properties of frazil in saline water. Cold Reg. Sci. Technol., 8(3), 209-221

Holland PR and Feltham DL (2005) Frazil dynamics and precipitation in a water column with depth-dependent supercooling. J. Fluid Mech., 530, 101-124 (doi: 10.1017/ S002211200400285X)

Jenkins A and Bombosch A (1995) Modeling the effects of frazil ice crystals on the dynamics and thermodynamics of ice shelf water plumes. J. Geophys. Res., 100(C4), 6967-6981

Kaufmann D (1960) Sodium chloride: the production and properties of salt and brine. American Chemical Society, Washington, DC

Kempema EW, Reimnitz E and Barnes PW (1989) Sea ice sediment entrainment and rafting in the Arctic. J. Sediment. Petrol., 59(2), 308-317

Lake RA and Lewis EL (1970) Salt rejection by sea ice during growth. J. Geophys. Res., 75(3), 583-597

Lewis EL and Lake RA (1971) Sea ice and supercooled water. J. Geophys. Res., 76(24), 5836-5841

Martin S (1981) Frazil ice in rivers and oceans. Annu. Rev. Fluid Mech., 13, 379-397

Martin S and Kauffman P (1974) The evolution of under-ice melt ponds, or double diffusion at the freezing point. J. Fluid Mech., 64(3), 507-528 (doi: 10.1017/S0022112074002527)

Martin S and Kauffman P (1981) A field and laboratory study of wave damping by grease ice. J. Glaciol., 27(96), 283-313

Martin S, Kauffman P and Welander PE (1977) A laboratory study of the dispersion of crude oil within sea ice grown in a wave field. In Proceeedings of the Twenty-seventh Alaska Science Conference, vol. II. American Association for the Advancement of Science, Fairbanks, AK, 261-287

MathWorks (2010) MATLAB, version 7.10 .0 (R2010a) Statistics Toolbox. The MathWorks Inc., Natick, MA

Maus S (2007) On brine entrapment in sea ice: morphological stability, microstructure and convection. Logos Verlag, Berlin

Maus S and 9 others (2009) Synchrotron-based X-ray tomography: insights into sea ice microstructure. In Leppäranta $M$ ed. Proceedings of the 6th Workshop on Baltic Sea Ice Climate, 2527 August 2008, Lammi Biological Station, Finland. University of Helsinki, Helsinki, 28-45

Maus $\mathrm{S}$ and 7 others (2011) lon fractionation in young sea ice from Kongsfjorden, Svalbard. Ann. Glaciol., 52(57 Pt 2), 301-310 (doi: 10.3189/172756411795931804)

McGuiness MJ, Williams MJM, Langhorne PJ, Purdie C and Crook J (2009) Frazil deposition under growing sea ice. J. Geophys. Res., 114(C7), C07014 (doi: 10.1029/2007JC004414)

Michaels AS, Brian PLT and Sperry PR (1966) Impurity effects on the basal plane solidification kinetics of supercooled water. J. Appl. Phys., 37(13), 4649-4661 (doi: 10.1063/1.1708113)

Michel B (1978) Ice mechanics. Presses de L'Université Laval, Québec
Millero FJ, Feistel R, Wright DG and McDougall TJ (2008) The composition of standard seawater and the definition of the reference-composition salinity scale. Deep-Sea Res. I, 55, 50-72

Morse B and Richard M (2009) A field study of suspended frazil ice particles. Cold Reg. Sci. Technol., 55(1), 86-102 (doi: 10.1016/j.coldregions.2008.03.004)

Nakawo M (1983) Measurements on air porosity of sea ice. Ann. Glaciol., 4, 204-208

Newyear K and Martin S (1997) A comparison of theory and laboratory measurements of wave propagation and attenuation in grease ice. J. Geophys. Res., 102(C11), 25 091-25 099

Omstedt A and Svensson U (1984) Modeling supercooling and ice formation in a turbulent Ekman layer. J. Geophys. Res., 89(C1), 735-744

Ono N (1967) Specific heat and heat of fusion of sea ice. In Oura $\mathrm{H}$ ed. Physics of snow and ice. Hokkaido University. Institute of Low Temperature Science, Sapporo, 599-610

Onstott RG, Grenfell TC, Perovich DK and Swift CT (1998) Electromagnetic and physical properties of sea ice formed in the presence of wave action. IEEE Trans. Geosci. Remote Sens., 36(5), 1764-1783

Pease $\mathrm{CH}$ (1987) The size of wind-driven coastal polynyas. J. Geophys. Res., 92(C7), 7049-7059

Pounder ER (1965) The physics of ice. Pergamon Press, Oxford

Pringle DJ, Miner JE, Eicken H and Golden KM (2009) Pore-space percolation in sea ice single crystals. J. Geophys. Res., 114(C12), C12017 (doi: 10.1029/2008JC005145)

Pronk P, Infante Ferreira CA and Witkamp GJ (2005) A dynamic model of Ostwald ripening in ice suspensions. J. Cryst. Growth, 275(1-2), e1355-e1361 (doi: 10.1016/j.jcrysgro.2004.11.173)

Rahli O, Tadrist L and Blanc R (1999) Experimental analysis of the porosity of randomly packed rigid fibres. C. R. Acad. Sci. [Paris], Sér. IIB, 327(8), 725-729 (doi: 0.1016/S1287-4620(99)80127-6)

Reimnitz E, Clayton JR, Jr, Kempema EW, Payne JR and Weber WS (1993) Interaction of rising frazil with suspended particles: tank experiments with applications to nature. Cold Reg. Sci. Technol., 21(2), 117-135

Shen HT ed. (1999) Ice in Surface Waters: Proceedings of the 14th International Symposium on Ice, 27-31 July 1998, Potsdam, New York, USA. Vols. 1 and 2. AA Balkema, Rotterdam

Smedsrud LH (2001) Frazil-ice entrainment of sediment: largetank laboratory experiments. J. Glaciol., 47(158), 461-471 (doi: 10.3189/172756501781832142)

Smedsrud LH and Skogseth R (2006) Field measurements of Arctic grease ice properties and processes. Cold Reg. Sci. Technol., 44(3), 171-183 (doi: 10.1016/j.coldregions.2005.11.002)

Song C, Wang P and Makse HA (2008) A phase diagram for jammed matter. Nature, 453(7195), 629-632 (doi: 10.1038/nature06981)

Svensson U and Omstedt A (1994) Simulation of supercooling and size distribution in frazil ice dynamics. Cold Reg. Sci. Technol., 22(3), 221-233

Thibert $\mathrm{E}$ and Domine $\mathrm{F}$ (1997) Thermodynamics and kinetics of the solid solution of $\mathrm{HCl}$ in ice. J. Phys. Chem., B, 101(18), 3554-3565

Tiller WA (1991) The science of crystallization: macroscopic phenomena and defect generation. Cambridge University Press, Cambridge

Tison J-L, Ronveaux D and Lorrain RD (1993) Low salinity frazil ice generation at the base of a small Antarctic ice shelf. Antarct. Sci., 5(3), 309-322

Tison, J-L, Haas C, Gowing MM, Sleewaegen S and Bernard A (2002) Tank study of physico-chemical controls on gas content and composition during growth of young ice, J. Glaciol., 48(161), 177-191

Torquato S, Truskett TM and Debenedetti PG (2000) Is random close packing of spheres well defined? Phys. Rev. Lett., 84(10), 20642067 (doi: 10.1103/PhysRevLett.84.2064)

Tsang G and Hanley TO (1985) Frazil formation in water of different salinities and supercoolings. J. Glaciol., 31(108), 74-85 
Tyshko KP and Cherepanov NV (1998) Supercooling of large water volumes: laboratory experiments. In Shen HT ed. Ice in Surface Waters: Proceedings of the 14th International Symposium on Ice, 27-31 July 1998, Potsdam, New York, USA. Balkema, Rotterdam, $371-377$

Untersteiner N and Sommerfeld R (1964) Supercooled water and the bottom topography of floating ice. J. Geophys. Res., 69(6), 1057-1062

Ushio S and Wakatsuchi M (1993) A laboratory study on supercooling and frazil ice production processes in winter coastal polynyas. J. Geophys. Res., 98(C11), 20321-20 328

Voropayev SI, Fernando HJS and Mitchell LA (1995) On the rate of frazil ice formation in polar regions in the presence of turbulence. J. Phys. Oceanogr., 26(6), 1441-1450

Wadhams P and Wilkinson JP (1999) The physical properties of sea ice in the Odden ice tongue. Deep-Sea Res. II, 46(6-7), 1275-1300

Wang R and Shen HH (2010) Experimental study of surface wave propagating through a grease-pancake ice mixture. Cold Reg. Sci. Technol., 61(23), 90-96

Wang SM and Doering JC (2005) Numerical simulation of supercooling process and frazil ice evolution. J. Hydraul. Eng., 131(10), 889-897 (doi: 10.1061/(ASCE)0733-9429(2005) 131:10(889))
Weeks WF and Gow AJ (1978) Preferred crystal orientations in the fast ice along the margins of the Arctic Ocean. J. Geophys. Res., 83(C10), 5105-5121

Weeks WF and Lofgren G (1967) The effective solute distribution coefficient during the freezing of $\mathrm{NaCl}$ solutions. In Oura $\mathrm{H}$ ed. Physics of snow and ice. Institute of Low Temperature Science, Hokkaido University, Sapporo, 579-597

White KD and Lawson DE (1992) Determining the intrinsic permeability of frazil ice. Pt. 2, Field investigations. CRREL Rep. 92-07

Wilkinson J (2005) Sea ice, convection and the Greenland Sea. (PhD thesis, University of Southampton)

Williams SR and Philipse AP (2003) Random packings of spheres and spherocylinders simulated by mechanical contraction. Phys. Rev. E, 67(5), 051301 (doi: 10.1103/PhysRevE.67.051301)

Wouterse A, Williams SR and Philipse AP (2007) Effect of particle shape on the density and microstructure of random packings. J. Phys. Condensed Matter, 19(40), 406215 (doi: 10.1088/ 0953-8984/19/40/406215)

Yokoyama E, Sekerka RF and Furukawa Y (2000) Growth trajectories of disk crystals of ice growing from supercooled water. J. Phys. Chem. B, 104(1), 65-67 (doi: 10.1021/jp991280b)

Zaytsev ID and Aseyev GG (1992) Properties of aqueous solutions of electrolytes. CRC Press, Boca Raton, FL

MS received 4 June 2011 and accepted in revised form 8 January 2012 